FEDERAL RESERVE BANK OF SAN FRANCISCO

WORKING PAPER SERIES

\title{
Can Pandemic-Induced Job Uncertainty Stimulate Automation?
}

\author{
Sylvain Leduc and Zheng Liu \\ Federal Reserve Bank of San Francisco \\ May 2020 \\ Working Paper 2020-19 \\ https://www.frbsf.org/economic-research/publications/working-papers/2020/19/
}

\section{Suggested citation:}

Leduc, Sylvain, Zheng Liu. 2020. “Can Pandemic-Induced Job Uncertainty Stimulate Automation?” Federal Reserve Bank of San Francisco Working Paper 2020-19.

https://doi.org/10.24148/wp2020-19

The views in this paper are solely the responsibility of the authors and should not be interpreted as reflecting the views of the Federal Reserve Bank of San Francisco or the Board of Governors of the Federal Reserve System. 


\title{
CAN PANDEMIC-INDUCED JOB UNCERTAINTY STIMULATE AUTOMATION?
}

\author{
SYLVAIN LEDUC AND ZHENG LIU
}

\begin{abstract}
The COVID-19 pandemic has raised concerns about the future of work. The pandemic may become recurrent, necessitating repeated adoptions of social distancing measures (voluntary or mandatory), creating substantial uncertainty about worker productivity. But robots are not susceptible to the virus. Thus, pandemic-induced job uncertainty may boost the incentive for automation. However, elevated uncertainty also reduces aggregate demand and reduces the value of new investment in automation. We assess the importance of automation in driving business cycle dynamics following an increase in job uncertainty in a quantitative New Keynesian DSGE framework. We find that, all else being equal, job uncertainty does stimulate automation, and increased automation helps mitigate the negative impact of uncertainty on aggregate demand.
\end{abstract}

\section{INTRODUCTION}

The COVID-19 pandemic has led to severe global economic disruptions. To slow the spread of the virus, countries have adopted strict social distancing measures and shelter-inplace orders. By shutting down non-essential businesses and forcing workers to stay home, these necessary public health policy measures contributed to further depressing economic activity.

The pandemic will eventually taper, allowing economic activity to recover. However, absent the discovery of vaccines and treatments, new waves of the pandemic may return, forcing governments to reintroduce social distancing and lockdown measures and thereby creating recurrent disruptions to economic activity. The distinct possibility of recurring future waves of the pandemic creates persistent uncertainty, which may have long-lasting impact on human behavior and economic activity. Reflecting the uncertainty caused by COVID-19, the VIX surged recently to levels above those observed during the global financial

Date: May 7, 2020.

Key words and phrases. Uncertainty, pandemic, robots, automation, productivity, unemployment, business cycles, monetary policy.

JEL classification: E24, E32, O33.

Leduc: Federal Reserve Bank of San Francisco. Email: Sylvain.Leduc@sf.frb.org. Liu: Federal Reserve Bank of San Francisco. Email: Zheng.Liu@sf.frb.org. We thank Lily Seitelman for excellent research assistance and Anita Todd for helpful editorial assistance. The views expressed herein are those of the authors and do not necessarily reflect the views of the Federal Reserve Bank of San Francisco or of the Federal Reserve System. 
crisis in 2008-09 (Figure 1). Anticipating potential future disruptions from the pandemic, households and firms may postpone long-term decisions, such as investment and hiring. The pandemic-induced uncertainty can thus have potentially important consequences for the depth of the downturn and the strength of the recovery.

In this paper, we examine the macroeconomic consequences of pandemic-induced uncertainty surrounding future labor productivity (hereafter, employment uncertainty). We focus on this type of uncertainty because the uncertain nature of the pandemic gives rise to uncertainty about future labor productivity. Workers can be exposed to health risks, and social distancing measures can reduce labor productivity by hindering the ability to work. But robots do not get sick. If a production process can be automated, a firm can use a robot instead of a worker to perform some risky tasks. In this sense, automation provides a hedge against job uncertainty stemming from the pandemic. However, a priori, job uncertainty may not necessarily translate into more automation, since higher uncertainty also reduces aggregate demand and has recessionary effects on the macroeconomy (Leduc and Liu, 2016). To assess the macro impact of the pandemic-induced job uncertainty when firms can automate to cope with future labor market disruptions, one needs a quantitative general equilibrium framework.

We provide such a framework. We build on Leduc and Liu (2019) and develop a New Keynesian model with automation and labor market search frictions. In line with Acemoglu and Restrepo (2018) and Zeira (1998), firms in our model first choose whether or not to adopt a robot to perform a set of tasks, and only nonautomated tasks (or vacancies) are available for hiring workers. We interpret automation as a labor-substituting technology. Thus, robots in our model are different from the physical capital in the standard macro models. In the beginning of each period, a firm observes an i.i.d. cost of automation and decides whether or not to automate an unfilled job position that is carried over from the previous period. If the cost of automation lies below a threshold determined by the net benefit of automation, then the firm adopts a robot for production and takes the job vacancy offline. The probability of automation is thus the cumulative density of automation costs evaluated at the automation threshold. If the job position is not automated, then the firm posts the vacancy in the labor market to search for a potential match with a job seeker. If the match is successful, the vacancy will be filled with a worker, and both the firm and the worker obtain their respective employment surplus from bargaining over the wage rate. If no match is formed, then the vacancy remains open and the firm obtains the continuation value of the vacancy, 
including the option to automate the position in future periods. ${ }^{1}$ We also show that our results are robust to assuming that firms can directly automate an existing job.

Firms' automation decisions partly depend on current and expected future worker productivity, which fluctuates due to labor-specific productivity shocks. These shocks capture the effects that the pandemic may have on workers' health and the impact of social distancing measures on their ability to work. We consider second-moment shocks to the labor-specific productivity in addition to the standard first-moment shocks. The productivity of robots is not subject to pandemic-related shocks, because the pandemic and the associated social distancing measures do not impede the robots' ability to operate. ${ }^{2}$

We incorporate price rigidities into this environment and estimate the model to fit quarterly U.S. time series data from 1985:Q1 to 2018:Q4. In our estimation, we do not consider pandemic-induced uncertainty shocks to labor-specific productivity, since pandemics are not observed in our sample. Therefore, the onset of the pandemic is unanticipated and the fluctuations in the observed macroeconomic variables have been driven by other shocks. We parameterize the model based on our estimation and calibration using the pre-2019 data. We then turn on the uncertainty shock to labor-specific productivity (i.e., job uncertainty) to examine its macroeconomic effects.

We show that a pandemic-induced job uncertainty leads firms to adopt more robots, which mitigates the recessionary effects from heightened uncertainty. An increase in uncertainty first contributes to a substantial and persistent increase in unemployment and a fall in inflation because uncertainty raises precautionary savings and reduces aggregate demand, similar to the effects in Leduc and Liu (2016). Other things being equal, the decline in economic activity reduces firms' incentives to automate, since the value of automation declines in a recession. However, heightened job uncertainty also boosts the incentive for firms to shift technologies toward automation, because the productivity of robots is not susceptible to the pandemic. Under our calibration, this technology-shifting effect dominates the recessionary effect such that the automation probability increases with job uncertainty. Since robots and workers are perfectly substitutable, the increase in automation reduces employment. Yet, increased automation also boosts employment through a separate channel, since the higher automation probability increases the value of a vacancy, resulting in more vacancy creation

\footnotetext{
${ }^{1}$ We interpret a job position broadly as consisting of a bundle of tasks, which are ex ante identical, but a fraction of which will be automated depending on the realization of the idiosyncratic costs of automation. This approach simplifies our analysis significantly. We have considered an alternative timing of the automation decisions, under which firms first post the job vacancies for hiring workers, and then decide whether or not to automate the unfilled vacancies. The results are similar.

${ }^{2}$ Automated processes may need human assistance. However, these operations can often be conducted remotely and are thus less subject to health risks and social distancing measures.
} 
and posting. In addition, the increase in automation raises labor productivity because more output can be produced with a given number of workers. Overall, while job uncertainty raises unemployment and reduces inflation, the option of automation mitigates these recessionary effects. $^{3}$

The pandemic-induced job uncertainty has markedly different effects from a reduction in the level of labor productivity. Both types of shocks generate a recession, but they operate through different channels. The uncertainty shock reduces aggregate demand and therefore pushes up unemployment and lowers inflation. In contrast, the first-moment shock reduces potential output and therefore raises both unemployment and inflation. More importantly, the two types of shocks have different impacts on automation. While uncertainty about worker productivity induces firms to shift technology toward automation and thus increases robot adoption, a negative labor productivity shock generates a large recession that reduces the incentive to automate. The decline in automation amplifies the initial negative shock to labor productivity.

Since the outbreak of the COVID-19 pandemic, there has been a burgeoning literature studying the impact of pandemics on the economy. Several studies attempt to shed light on the economic impact of COVID-19 and the effectiveness of public health policy interventions based on historical experience such as the 1918 Spanish flu pandemic or the 2003 SARS outbreak. ${ }^{4}$ There have also been a growing number of theoretical studies on the economic impact of the pandemic and the efficacy of alternative policy interventions. Some of these theoretical studies build on the susceptible-infected-recovered (SIR) framework initially proposed by Kermack and McKendrick (1927). ${ }^{5}$ Some other studies build on the New Keynesian framework and incorporate features that capture the disruptive effects of pandemic shocks on economic activity. ${ }^{6}$

Our work complements this literature. While the existing studies examine the direct disruptive effects of the pandemic on the economy, we focus on the business cycle dynamics

\footnotetext{
${ }^{3}$ Our model's implication that automation rises in a recession is consistent with empirical evidence. For example, Hershbein and Kahn (2018) use MSA and firm-level data to show that, in the 2008-09 Great Recession, firms raised skill requirements for workers and increased capital investment, such that the recession accelerated routine-biased technological changes. Jaimovich and Siu (2018) also show that job losses in routine occupations have been concentrated in economic downturns since the mid-1980s, and the disappearance of the routine-skill jobs has contributed to the jobless recoveries. To the extent that automation displaces jobs in routine occupations, these empirical findings lend support to our theory.

${ }^{4}$ Examples include Correia et al. (2020), Barro et al. (2020), Jorda et al. (2020), Ma et al. (2020), and Fang et al. (2020), among others.

${ }^{5}$ Examples include Atkeson (2020), Berger et al. (2020b), Chudik et al. (2020), Eichenbaum et al. (2020), Garibaldi et al. (2020), Glover et al. (2020), and Jones et al. (2020), among many others.

${ }^{6}$ Examples include Faria e Castro (2020) and Guerrieri et al. (2020), among others.
} 
triggered by the pandemic. In particular, we examine how increases in job uncertainty associated with worker health risks would drive macroeconomic fluctuations. In this sense, our paper also contributes to the literature about the macroeconomic effects of uncertainty shocks. ${ }^{7}$ We show that a shock to job uncertainty has markedly different macroeconomic effects than the standard first-moment shock to labor productivity, and that the option to automate a production process enables firms to mitigate the adverse impact of uncertainty. To our knowledge, the automation channel for the transmission of pandemic-induced uncertainty is novel to the literature. ${ }^{8}$

\section{The New Keynesian model With aUtomation and Labor market Frictions}

We present a New Keynesian model with automation and labor market frictions. The model builds on Leduc and Liu (2019) and incorporates nominal rigidities and uncertainty shocks. Final goods output is the sum of the intermediate goods produced by workers and by robots. Since robots are perfect substitutes for workers in production, they are different from the physical capital in the standard neoclassical production functions, where capital and labor are complementary inputs. ${ }^{9}$ Retailers use intermediate goods to produce differentiated consumption goods subject to nominal rigidities. The final good, an aggregate of the differentiated goods, is used for household consumption and also for paying the costs of vacancy posting, vacancy creation, and robot adoption.

To keep automation decisions tractable, we impose some assumptions on the timing of events. In the beginning of period $t$, a job separation shock $\delta_{t}$ is realized. Workers who lose their jobs add to the stock of unemployment from the previous period, forming the

\footnotetext{
${ }^{7}$ The literature on uncertainty shocks has grown rapidly since the important contribution of Bloom (2009). It is beyond the scope of our paper to provide an exhaustive list of the recent contributions to this literature. For recent surveys of this literature, see Bloom (2014) and Fernández-Villaverde and GuerrónQuintana (2020). Dietrich et al. (2020) provide survey-based evidence that COVID-19 has induced large uncertainty in household expectations of future output growth and inflation. For other recent empirical studies of the macroeconomic effects of uncertainty induced by COVID-19, see Baker et al. (2020) and Leduc and Liu (2020a). Our focus on the impact of uncertainty shocks on labor market outcomes in a framework with search frictions is related to that in Leduc and Liu (2016) and den Haan et al. (2020).

${ }^{8}$ Recent contributions to the literature on automation and the labor market include, for example, Autor (2015), Acemoglu and Restrepo (2017, 2018), Graetz and Michaels (2018), Leduc and Liu (2019), and Jaimovich et al. (2020).

${ }^{9}$ Krusell et al. (2000) study a neoclassical model in which capital equipment complements skilled labor but substitutes for unskilled labor. The relation between robots and workers in our model is analogous to the relation between equipment and unskilled labor in their model. For simplicity, we abstract from labor heterogeneity (skilled vs. unskilled). See He and Liu (2008) for a general equilibrium version of the model with skill accumulations and equipment-skill complementarity.
} 
pool of job seekers $u_{t}$. Firms post vacancies $v_{t}$ at a fixed cost $\kappa$. The stock of vacancies $v_{t}$ includes the unfilled vacancies that were not automated at the end of period $t-1$, the jobs separated in the beginning of period $t$, and new vacancies created in the beginning of period t. Creating a new vacancy incurs a fixed cost, which is drawn from an i.i.d. distribution $G(\cdot)$, as in Leduc and Liu (2019). In the labor market, a matching technology transforms job seekers and vacancies into an employment relation, with a wage rate determined through Nash bargaining between the employer and the job seeker. Once an employment relation is formed, production takes place, and the firm receives the employment value. An unfilled vacancy can be either carried forward to the next period or automated at a fixed cost. Similar to the vacancy creation cost, the automation cost $x$ is drawn from an i.i.d. distribution $F(x)$. If a firm draws an automation cost that is below a threshold value $x_{t}^{*}$, then the firm adopts a robot and closes the job opening. In that case, the firm obtains the automation value. Otherwise, the vacancy remains open and the firm receives the continuation value of the vacancy. Newly adopted robots add to the stock of automation, which becomes obsolete over time at a constant rate $\rho^{o}$.

II.1. The Labor Market. In the beginning of period $t$, there are $N_{t-1}$ existing job matches. A job separation shock displaces a fraction $\delta_{t}$ of those matches, so that the measure of unemployed job seekers is given by

$$
u_{t}=1-\left(1-\delta_{t}\right) N_{t-1}
$$

where we have assumed full labor force participation and normalized the size of the labor force to one.

The job separation rate shock $\delta_{t}$ follows the stationary stochastic process

$$
\ln \delta_{t}=\left(1-\rho_{\delta}\right) \ln \bar{\delta}+\rho_{\delta} \ln \delta_{t-1}+\sigma_{\delta} \varepsilon_{\delta t},
$$

where $\rho_{\delta}$ is the persistence parameter, $\sigma_{\delta}$ denotes the standard deviation of the innovation, and the term $\varepsilon_{\delta t}$ is an i.i.d. standard normal process. The term $\bar{\delta}$ denotes the mean rate of job separation.

The stock of vacancies $v_{t}$ in the beginning of period $t$ consists of the vacancies in period $t-1$ that were not filled with workers and not automated, plus the separated employment matches and newly created vacancies. The law of motion for vacancies is given by

$$
v_{t}=\left(1-q_{t-1}^{v}\right)\left(1-q_{t-1}^{a}\right) v_{t-1}+\delta_{t} N_{t-1}+\eta_{t}
$$

where $q_{t-1}^{v}$ denotes the job filling rate in period $t-1, q_{t-1}^{a}$ denotes the automation rate in period $t-1$, and $\eta_{t}$ denotes the newly created vacancies (i.e., entry). 
In the labor market, new job matches (denoted by $m_{t}$ ) are formed between job seekers and open vacancies based on the matching function

$$
m_{t}=\mu u_{t}^{\alpha} v_{t}^{1-\alpha}
$$

where $\mu$ is a scale parameter that measures match efficiency and $\alpha \in(0,1)$ is the elasticity of job matches with respect to the number of job seekers.

The flow of new job matches adds to the employment pool, and job separations subtract from it. Aggregate employment evolves according to the law of motion

$$
N_{t}=\left(1-\delta_{t}\right) N_{t-1}+m_{t} .
$$

At the end of period $t$, the searching workers who failed to find a job match remain unemployed. Thus, unemployment is given by

$$
U_{t}=u_{t}-m_{t}=1-N_{t} .
$$

For convenience, we define the job finding probability $q_{t}^{u}$ as

$$
q_{t}^{u}=\frac{m_{t}}{u_{t}} .
$$

Similarly, we define the job filling probability $q_{t}^{v}$ as

$$
q_{t}^{v}=\frac{m_{t}}{v_{t}} .
$$

II.2. The firms. A firm makes automation decisions in the beginning of the period $t$. Adopting a robot requires a fixed cost $x$ in units of consumption goods. The fixed cost is drawn from the i.i.d. distribution $G(x)$. A firm chooses to adopt a robot if and only if the cost of automation is less than the benefit. For any given benefit of automation, there exists a threshold value $x_{t}^{*}$ in the support of the distribution $G(x)$, such that automation occurs if and only if $x \leq x_{t}^{*}$. If the firm adopts a robot to replace the job position, then the vacancy will be taken offline and not available for hiring a worker. Thus, the automation threshold $x_{t}^{*}$ depends on the value of automation (denoted by $J_{t}^{a}$ ) relative to the value of a vacancy (denoted by $J_{t}^{v}$ ). In particular, the threshold for automation decision is given by

$$
x_{t}^{*}=J_{t}^{a}-J_{t}^{v} .
$$

The probability of automation is then given by the cumulative density of the automation costs evaluated at $x_{t}^{*}$. That is,

$$
q_{t}^{a}=G\left(x_{t}^{*}\right) .
$$

The flow of automated job positions adds to the stock of automatons (denoted by $A_{t}$ ), which becomes obsolete at the rate $\rho^{o} \in[0,1]$ in each period. Thus, $A_{t}$ evolves according to the law of motion

$$
A_{t}=\left(1-\rho^{o}\right) A_{t-1}+q_{t}^{a}\left(1-q_{t-1}^{v}\right) v_{t-1},
$$


where $q_{t}^{a}\left(1-q_{t-1}^{v}\right) v_{t-1}$ is the number of newly automated job positions.

Once adopted, a robot produces $Z_{t} \zeta_{a t}$ units of output, where $Z_{t}$ denotes a neutral technology shock and $\zeta_{a t}$ denotes an automation-specific shock. The neutral technology shock $Z_{t}$ follows the stochastic process

$$
\ln Z_{t}=\left(1-\rho_{z}\right) \ln \bar{Z}+\rho_{z} \ln Z_{t-1}+\sigma_{z} \varepsilon_{z t} .
$$

The parameter $\rho_{z} \in(-1,1)$ measures the persistence of the technology shock and $\sigma_{z}$ is the standard deviation of the innovation. The term $\varepsilon_{z t}$ is an i.i.d. standard normal process. The term $\bar{Z}$ is the steady-state level of the technology shock. ${ }^{10}$ The automation-specific technology shock $\zeta_{a t}$ follows a stochastic process that is independent of the neutral technology shock $Z_{t}$. In particular, $\zeta_{a t}$ follows the stationary process

$$
\ln \zeta_{a t}=\left(1-\rho_{a}\right) \ln \bar{\zeta}_{a}+\rho_{a} \ln \zeta_{a, t-1}+\sigma_{a} \varepsilon_{a t} .
$$

The parameter $\rho_{a} \in(-1,1)$ measures the persistence of the automation-specific technology shock, the term $\bar{\zeta}$ is the steady-state level of the automation-specific technology shock, the term $\sigma_{a}$ denotes the standard deviation of the innovation, and the term $\varepsilon_{\zeta t}$ is an i.i.d. standard normal process.

Operating the robot incurs a flow fixed cost of $\kappa_{a}$. The value of automation satisfies the Bellman equation

$$
J_{t}^{a}=p_{m t} Z_{t} \zeta_{a t}\left(1-\kappa_{a}\right)+\left(1-\rho^{o}\right) \mathbb{E}_{t} D_{t, t+1} J_{t+1}^{a},
$$

where $p_{m t}$ denotes the relative price of intermediate goods (in units of final consumption goods), the term $\kappa_{a}$ captures the flow costs of automated production (such as energy, facilities, and space rental), and $D_{t, t+1}$ is a stochastic discount factor of the households.

If the automation cost exceeds the threshold $x_{t}^{*}$, then the vacancy will be posted in the labor market for hiring a worker. In addition, newly separated jobs and newly created vacancies add to the stock of vacancies for hiring workers. Following Leduc and Liu (2020b), we assume that creating a new vacancy incurs an entry cost $e$ in units of consumption goods. The entry cost is drawn from an i.i.d. distribution $F(e)$. A new vacancy is created if and only if the net value of entry is non-negative. The benefit of creating a new vacancy is the vacancy value $J_{t}^{v}$. Thus, the number of new vacancies $\eta_{t}$ is given by the cumulative density of the entry costs evaluated at $J_{t}^{v}$. That is,

$$
\eta_{t}=F\left(J_{t}^{v}\right)
$$

Posting a vacancy incurs a per-period fixed cost $\kappa$ (in units of final consumption goods). If the vacancy is filled (with the probability $q_{t}^{v}$ ), the firm obtains the employment value

\footnotetext{
${ }^{10}$ The model can easily be extended to allow for trend growth. We do not present that version of the model to simplify presentation.
} 
$J_{t}^{e}$. Otherwise, the firm carries over the unfilled vacancy to the next period, which will be automated with the probability $q_{t+1}^{a}$. If the vacancy is automated, then the firm obtains the automation value $J_{t+1}^{a}$; otherwise, the vacancy will remain open, and the firm receives the continuation value $J_{t+1}^{v}$. Thus, the vacancy value satisfies the Bellman equation

$$
J_{t}^{v}=-\kappa+q_{t}^{v} J_{t}^{e}+\left(1-q_{t}^{v}\right) \mathbb{E}_{t} D_{t, t+1}\left[q_{t+1}^{a} J_{t+1}^{a}+\left(1-q_{t+1}^{a}\right) J_{t+1}^{v}\right] .
$$

If a firm successfully hires a worker, then it can produce $Z_{t} \zeta_{l t}$ units of intermediate goods. The term $\zeta_{l t}=\bar{\zeta}_{l}$ measures the relative efficiency of workers, capturing the disruptions of the COVID-19 pandemic on worker productivity. Since the pandemic was not observed in our sample that ends in 2018, we keep $\zeta_{l t}$ constant at its average value $\bar{\zeta}_{l}$ for calibrating and estimating the model parameters and shock processes. When we study the macroeconomic implications of the pandemic-induced job uncertainty, we turn on the $\zeta_{l t}$ shock, and study the transmission channels of both the first-moment shock (which captures disruptions of the pandemic to the level of worker productivity) and the second-moment shock (which captures the job uncertainty stemming from the pandemic).

The value of employment satisfies the Bellman equation

$$
J_{t}^{e}=p_{m t} Z_{t} \zeta_{l t}-w_{t}+\mathbb{E}_{t} D_{t, t+1}\left\{\left(1-\delta_{t+1}\right) J_{t+1}^{e}+\delta_{t+1} J_{t+1}^{v}\right\},
$$

where $w_{t}$ denotes the real wage rate. Hiring a worker generates a flow profit $p_{m t} Z_{t} \zeta_{l t}-w_{t}$ in the current period. If the job is separated in the next period (with probability $\delta_{t+1}$ ), then the firm receives the vacancy value $J_{t+1}^{v}$. Otherwise, the firm receives the continuation value of employment.

II.3. The representative household. The representative household has the utility function

$$
\mathbb{E} \sum_{t=0}^{\infty} \beta^{t} \Theta_{t}\left[\ln \left(C_{t}-\gamma_{c} C_{t-1}\right)-\chi N_{t}\right]
$$

where $\mathbb{E}[\cdot]$ is an expectation operator, $C_{t}$ denotes consumption, and $N_{t}$ denotes the fraction of household members who are employed. The parameter $\beta \in(0,1)$ denotes the subjective discount factor, the parameter $\gamma_{c}$ measures habit persistence, and the term $\Theta_{t}$ denotes an exogenous shifter to the subjective discount factor.

The discount factor shock $\theta_{t} \equiv \frac{\Theta_{t}}{\Theta_{t-1}}$ follows the stationary stochastic process

$$
\ln \theta_{t}=\rho_{\theta} \ln \theta_{t-1}+\sigma_{\theta} \varepsilon_{\theta t} .
$$

In this shock process, $\rho_{\theta}$ is the persistence parameter, $\sigma_{\theta}$ is the standard deviation of the innovation, and the term $\varepsilon_{\theta t}$ is an i.i.d. standard normal process. Here, we have implicitly assumed that the mean value of $\theta$ is one. 
The representative household chooses consumption $C_{t}$ and savings $B_{t}$ to maximize the utility function (18) subject to the sequence of budget constraints

$$
C_{t}+\frac{B_{t}}{R_{t} P_{t}}=\frac{B_{t-1}}{P_{t}}+w_{t} N_{t}+\phi\left(1-N_{t}\right)+d_{t}-T_{t}, \quad \forall t \geq 0,
$$

where $R_{t}$ denotes the gross nominal interest rate, $d_{t}$ denotes the household's share of firm profits, and $T_{t}$ denotes lump-sum taxes. The aggregate price of final consumption goods is given by $P_{t}$. The parameter $\phi$ measures the flow benefits of unemployment.

Denote by $V_{t}\left(B_{t-1}, N_{t-1}\right)$ the value function for the representative household. The household's optimizing problem can be written in the recursive form

$$
V_{t}\left(B_{t-1}, N_{t-1}\right) \equiv \max \ln \left(C_{t}-\gamma_{c} C_{t-1}\right)-\chi N_{t}+\beta \mathbb{E}_{t} \theta_{t+1} V_{t+1}\left(B_{t}, N_{t}\right),
$$

subject to the budget constraint (20) and the employment law of motion (5), the latter of which can be written as

$$
N_{t}=\left(1-\delta_{t}\right) N_{t-1}+q^{u} u_{t},
$$

where we have used the definition of the job finding probability $q_{t}^{u}=\frac{m_{t}}{u_{t}}$, with the measure of job seekers $u_{t}$ given by Eq. (1). In the optimizing decisions, the household takes the economy-wide job finding rate $q_{t}^{u}$ as given.

Define the employment surplus (i.e., the value of employment relative to unemployment) as $S_{t}^{H} \equiv \frac{1}{\Lambda_{t}} \frac{\partial V_{t}\left(B_{t-1}, N_{t-1}\right)}{\partial N_{t}}$, where the marginal utility of consumption is given by

$$
\Lambda_{t}=\frac{1}{C_{t}-\gamma_{c} C_{t-1}}-\mathbb{E}_{t} \beta \theta_{t+1} \gamma_{c} \frac{1}{C_{t+1}-\gamma_{c} C_{t}} .
$$

We show in Appendix A that the employment surplus satisfies the Bellman equation

$$
S_{t}^{H}=w_{t}-\phi-\frac{\chi}{\Lambda_{t}}+\mathbb{E}_{t} D_{t, t+1}\left(1-q_{t+1}^{u}\right)\left(1-\delta_{t+1}\right) S_{t+1}^{H},
$$

where $D_{t, t+1} \equiv \frac{\beta \theta_{t+1} \Lambda_{t+1}}{\Lambda_{t}}$ is the stochastic discount factor, which applies to both the household's intertemporal optimization and firms' decisions.

The employment surplus has a straightforward economic interpretation. If the household adds a new worker in period $t$, then the current-period gain would be wage income net of the opportunity costs of working, including unemployment benefits and the disutility of working. The household also enjoys the continuation value of employment if the employment relation continues. Having an extra worker today adds to the employment pool tomorrow (if the employment relation survives job separation); however, adding a worker today would also reduce the pool of searching workers tomorrow, a fraction $q_{t+1}^{u}$ of whom would be able to find jobs. Thus, the marginal effect of adding a new worker in period $t$ on employment in period $t+1$ is given by $\left(1-q_{t+1}^{u}\right)\left(1-\delta_{t+1}\right)$, resulting in the effective continuation value of employment shown in the last term of Eq. (24). 
We also show in Appendix A that the household's optimizing consumption-savings decision implies the intertemporal Euler equation

$$
1=\mathbb{E}_{t} D_{t, t+1} \frac{R_{t}}{\pi_{t+1}}
$$

where $\pi_{t+1}=\frac{P_{t+1}}{P_{t}}$ denotes the inflation rate.

II.4. The Nash bargaining wage. When a job match is formed, the wage rate is determined through Nash bargaining. The bargaining wage optimally splits the joint surplus of a job match between the worker and the firm. The worker's employment surplus is given by $S_{t}^{H}$ in Eq. (24). The firm's surplus is given by $J_{t}^{e}-J_{t}^{v}$. The possibility of automation affects the value of a vacancy and thus indirectly affects the firm's reservation value and its bargaining decisions.

The Nash bargaining problem is given by

$$
\max _{w_{t}}\left(S_{t}^{H}\right)^{b}\left(J_{t}^{e}-J_{t}^{v}\right)^{1-b},
$$

where $b \in(0,1)$ represents the bargaining weight for workers.

Define the total surplus as

$$
S_{t} \equiv J_{t}^{e}-J_{t}^{v}+S_{t}^{H}
$$

Then the bargaining solution is given by

$$
J_{t}^{e}-J_{t}^{v}=(1-b) S_{t}, \quad S_{t}^{H}=b S_{t}
$$

The bargaining outcome implies that the firm's surplus is a constant fraction $1-b$ of the total surplus $S_{t}$ and the household's surplus is a fraction $b$ of the total surplus.

The bargaining solution (28) and the expression for household surplus in equation (24) together imply that the Nash bargaining wage $w_{t}^{N}$ satisfies the Bellman equation

$$
\begin{aligned}
\frac{b}{1-b}\left(J_{t}^{e}-J_{t}^{v}\right)= & w_{t}^{N}-\phi-\frac{\chi}{\Lambda_{t}} \\
& +\mathbb{E}_{t} D_{t, t+1}\left(1-q_{t+1}^{u}\right)\left(1-\delta_{t+1}\right) \frac{b}{1-b}\left(J_{t+1}^{e}-J_{t+1}^{v}\right) .
\end{aligned}
$$

We do not impose any real wage rigidities. Thus, the equilibrium real wage rate is just the Nash bargaining wage rate. That is, $w_{t}=w_{t}^{N}$.

II.5. The Aggregation Sector. Denote by $Y_{t}$ the final consumption good, which is a basket of differentiated retail goods. Denote by $Y_{t}(j)$ a type $\mathrm{j}$ retail good for $\mathrm{j} \in[0,1]$. We assume that

$$
Y_{t}=\left(\int_{0}^{1} Y_{t}(j)^{\frac{\epsilon-1}{\epsilon}}\right)^{\frac{\epsilon}{\epsilon-1}}
$$


where epsilon $>1$ is the elasticity of substitution between differentiated products. Expenditure minimizing implies that demand for a type $\mathrm{j}$ retail good is inversely related to the relative price, with the demand schedule given by

$$
Y_{t}^{d}(j)=\left(\frac{P_{t}(j)}{P_{t}}\right)^{-\epsilon} Y_{t}
$$

where $Y_{t}^{d}(j)$ and $P_{t}(j)$ denote the demand for and the price of a retail good of type $\mathrm{j}$, respectively. Zero profit in the aggregation sector implies that the price index $P_{t}$ is related to the individual prices $P_{t}(j)$ through the relation

$$
P_{t}=\left(\int_{0}^{1} P_{t}(j)^{\frac{1}{1-\epsilon}}\right)^{1-\epsilon}
$$

II.6. The retail goods producers. There is a continuum of retailers, each producing a differentiated product using a homogeneous intermediate good as input. The production function of a retail good of type $\mathrm{j} \in[0,1]$ is given by

$$
Y_{t}(j)=X_{t}(j)
$$

where $X_{t}(j)$ is the input of intermediate goods used by retailer $\mathrm{j}$ and $Y_{t}(j)$ is the output. The retail goods producers are price takers in the input market and monopolistic competitor in the product markets, where they set prices for their products, taking as given the demand schedule and the price index.

Following Rotemberg (1982), we assume that price adjustments are subject to the quadratic cost

$$
\frac{\Omega_{p}}{2}\left(\frac{P_{t}(j)}{\pi_{t-1}^{\gamma_{p}} \pi^{1-\gamma_{p}} P_{t-1}(j)}-1\right)^{2} Y_{t}
$$

where the parameter $\Omega_{p} \geq 0$ measures the cost of price adjustments and $\gamma_{p}$ is the parameter for dynamic inflation indexation (Christiano et al., 2005).

Price adjustment costs are in units of aggregate output. A retail firm that produces good j chooses $P_{t}(j)$ to maximize profit

$$
E_{t} \sum_{i=0}^{\infty} \frac{\beta^{i} \theta_{t+i} \Lambda_{t+i}}{\Lambda_{t}}\left[\left(\frac{P_{t+i}(j)}{P_{t+i}}-p_{m, t+i}\right) Y_{t+i}^{d}(j)-\frac{\Omega_{p}}{2}\left(\frac{P_{t+i}(j)}{\pi_{t+i-1}^{\gamma_{p}} \pi^{1-\gamma_{p}} P_{t+i-1}(j)}-1\right)^{2} Y_{t+i}\right] .
$$

The optimal price-setting decision implies that, in a symmetric equilibrium with $P_{t}(j)=P_{t}$ for all $\mathrm{j}$, we have

$p_{m t}=\frac{\epsilon-1}{\epsilon}+\frac{\Omega_{p}}{\epsilon}\left[\frac{\pi_{t}}{\pi_{t-1}^{\gamma_{p}} \pi^{1-\gamma_{p}}}\left(\frac{\pi_{t}}{\pi_{t-1}^{\gamma_{p}} \pi^{1-\gamma_{p}}}-1\right)-E_{t} \frac{\beta \theta_{t+1} \Lambda_{t+i}}{\Lambda_{t}} \frac{Y_{t+1}}{Y_{t}} \frac{\pi_{t+1}}{\pi_{t}^{\gamma_{p}} \pi^{1-\gamma_{p}}}\left(\frac{\pi_{t+1}}{\pi_{t}^{\gamma_{p}} \pi^{1-\gamma_{p}}}-1\right)\right]$.

Absent price adjustment costs (i.e., $\Omega_{p}=0$ ), the optimal pricing rule implies that real marginal cost $p_{m t}$ equals the inverse of the price markup (with the markup given by $\mu_{p}=\frac{\epsilon}{\epsilon-1}$ ). 
II.7. Government policy. The monetary authority follows the Taylor rule

$$
\frac{R_{t}}{R}=\left(\frac{R_{t-1}}{R}\right)^{\rho_{r}}\left[\left(\frac{\pi_{t}}{\pi}\right)^{\phi_{\pi}}\left(\frac{U_{t}}{U_{t}^{*}}\right)^{-\frac{\phi_{u}}{4}}\right]^{1-\rho_{f}} \exp \left(\varepsilon_{r t}\right)
$$

where the inflation target is given by the steady-state inflation rate $\pi, U_{t}^{*}$ denotes the unemployment rate in the flexible-price equilibrium (i.e., the natural rate of unemployment), and $\varepsilon_{r t}$ is an i.i.d. monetary policy shock. The parameter $\rho_{r}$ measures the persistence of the interest rate adjustments (i.e., interest-rate smoothing). The parameters $\phi_{\pi}$ and $\phi_{u}$ measure the responsiveness of the interest rate to deviations of inflation from the target and changes in the unemployment gap, respectively.

The government finances an exogenous stream of spending $G_{t}$ and unemployment benefit payments $\phi$ through lump-sum taxes. We assume that the government balances the budget in each period such that

$$
G_{t}+\phi\left(1-N_{t}\right)=T_{t}
$$

The government spending shock $G_{t}$ follows the stationary stochastic process

$$
\ln G_{t}=\left(1-\rho_{g}\right) \ln \bar{G}+\rho_{g} \ln G_{t-1}+\sigma_{g} \varepsilon_{g t} .
$$

The term $\bar{G}$ denotes the mean level of government spending, the parameter $\rho_{g}$ measures the persistence of the shock, and the parameter $\sigma_{g}$ denotes the standard deviation of the innovation. The term $\varepsilon_{g t}$ is an i.i.d. standard normal process.

II.8. Search equilibrium. In a search equilibrium, the markets for bonds and goods both clear. Since the aggregate bond supply is zero, the bond market-clearing condition implies that

$$
B_{t}=0 \text {. }
$$

Goods market clearing requires that consumption, government spending, vacancy posting costs, automation costs, vacancy creation costs, and price adjustment costs add up to aggregate production. This requirement yields the aggregate resource constraint

$C_{t}+G_{t}+\kappa v_{t}+\kappa_{a} Z_{t} \zeta_{a t} A_{t}+\left(1-q_{t-1}^{v}\right) v_{t-1} \int_{0}^{x_{t}^{*}} x d G(x)+\int_{0}^{J_{t}^{v}} e d F(e)+\frac{\Omega_{p}}{2}\left(\frac{\pi_{t}}{\pi}-1\right)^{2} Y_{t}=Y_{t}$,

where $Y_{t}$ denotes aggregate output, which equals the sum of goods produced by workers and by robots and is given by

$$
Y_{t}=Z_{t} \zeta_{l t} N_{t}+Z_{t} \zeta_{a t} A_{t}
$$

The equilibrium conditions are summarized in Appendix B. 


\section{Empirical Strategies}

We use the model to study the macro impact of job uncertainty (i.e., the second-moment shock to worker-specific productivity). For this purpose, we solve the model based on thirdorder approximations to the equilibrium conditions. ${ }^{11}$ To solve the model requires assigning values to the parameters. We first calibrate a subset of the parameters to match steadystate observations and the empirical literature. We then estimate the remaining structural parameters and the shock processes to fit U.S. time-series data. To estimate the model, we solve the log-linearized equilibrium conditions around the steady state and fit the model to the data. In our estimation, we keep work-specific productivity constant (i.e., $\zeta_{l t}=\bar{\zeta}_{l}$ ). Since COVID-19 was not observed in our data sample from 1985 to 2018, we view that the pandemic-induced shocks to worker productivity - both the first moment and the second moment shocks - have not been an important source of macroeconomic fluctuations in our sample. We then use the estimated model to examine the macroeconomic effects of the pandemic-induced shocks to both the level and the uncertainty about worker productivity.

We focus on the parameterized distribution functions

$$
F(e)=\left(\begin{array}{l}
e \\
\overline{\bar{e}}
\end{array}\right)^{\eta_{v}}, \quad G(x)=\left(\frac{x}{\bar{x}}\right)^{\eta_{a}}
$$

where $\bar{e}>0$ and $\bar{x}>0$ are the scale parameters and $\eta_{v}>0$ and $\eta_{a}>0$ are the shape parameters of the distribution functions. Following Leduc and Liu (2019), we set $\eta_{v}=1$ and $\eta_{a}=1$, so that both the vacancy creation cost and the automation cost follow a uniform distribution. We estimate the scale parameters $\bar{e}$ and $\bar{x}$ and the shock processes by fitting the model to U.S. time series data.

III.1. Steady-state equilibrium and parameter calibration. Table 1 shows the calibrated parameter values. We consider a quarterly model. We set the subjective discount factor to $\beta=0.99$, so that the model implies an annualized real interest rate of about 4 percent in the steady state. We set the matching function elasticity to $\alpha=0.5$, in line with the literature (Blanchard and Galí, 2010; Gertler and Trigari, 2009). Following Hall and Milgrom (2008), we set the worker bargaining weight to $b=0.5$ and the unemployment benefit parameter to $\phi=0.25$. Based on the data from the Job Openings and Labor Turnover Survey (JOLTS), we calibrate the steady-state job separation rate to $\bar{\delta}=0.10$ at the quarterly frequency. We set $\rho^{o}=0.03$, so that robots depreciate at an average annual rate of 12 percent. We normalize the level of labor productivity to $\bar{Z}=1$, the worker-specific productivity to $\bar{\zeta}_{l}=1$, and automation-specific productivity to $\bar{\zeta}_{a}=1$. We calibrate $\epsilon=11$,

\footnotetext{
${ }^{11}$ We summarize the equilibrium conditions, the steady state, and the log-linearized system in the appendix. For a description of the solution methods, see Leduc and Liu (2016).
} 
implying a 10 percent average retail price markup (i.e., $\mu_{p}=1.1$ ). Given the markup, we obtain the steady-state relative price of intermediate goods given by $p_{m}=\frac{1}{\mu_{p}}$.

We target a steady-state unemployment rate of $U=0.059$, corresponding to the average unemployment rate in our sample from 1985 to 2018. The steady-state employment is then given by $N=1-U$, hiring rate by $m=\bar{\delta} N$, the number of job seekers by $u=1-(1-\bar{\delta}) N$, and the job finding rate by $q^{u}=\frac{m}{u}$. We target a steady-state job filling rate of $q^{v}=0.71$ per quarter, in line with the calibration of den Haan et al. (2000). The implied stock of vacancies is $v=\frac{m}{q^{v}}$. The scale of the matching efficiency is then given by $\mu=\frac{m}{u^{\alpha} v^{1-\alpha}}=0.66$. We set the flow cost of operating robots to $\kappa_{a}=0.98$. Given the average productivities $\bar{Z}=\bar{\zeta}_{a}=1$, this implies a quarterly profit of 1.8 percent of the revenue by using a robot for production. The steady-state automation value $J^{a}$ can then be solved from the Bellman equation (14).

Conditional on $J^{a}$ and the estimated values of $\bar{e}$ and $\bar{x}$ (see below for estimation details), we use the vacancy creation condition (15), the automation adoption condition (9), and law of motion for vacancies (3) to obtain the steady-state probability of automation, which is given by

$$
q^{a}=\frac{J^{a}}{\bar{x}+\beta \bar{e}\left(1-q^{v}\right) v} .
$$

Given $q^{a}$ and $v$, the law of motion for vacancies implies that the flow of new vacancies is given by $\eta=q^{a}\left(1-q^{v}\right) v$. The vacancy value is then given by $J^{v}=\bar{e} \eta$. The stock of automation $A$ can be solved from the law of motion (11), which reduces to $\rho^{o} A=q^{a}(1-$ $\left.q^{v}\right) v=\eta$ in the steady state. Thus, in the steady state, the newly created vacancies equal the flow of automated jobs that become obsolete.

With $A$ and $N$ solved, we obtain the aggregate output $Y=\bar{Z}\left(\bar{\zeta}_{l} N+\bar{\zeta}_{a} A\right)$. We calibrate the vacancy posting cost to $\kappa=0.0918$, so that the steady-state vacancy posting cost is 1 percent of aggregate output (i.e., $\kappa v=0.01 Y$ ).

Given $J^{v}$ and $J^{a}$, we obtain the cutoff point for robot adoption $x^{*}=J^{a}-J^{v}$. The match value $J^{e}$ can be solved from the Bellman equation for vacancies (16), and the equilibrium real wage rate can be obtained from the Bellman equation for employment (17). Steady-state consumption is solved from the resource constraint (41). We then infer the value of $\chi$ from the expression for bargaining surplus in Eq. (29).

III.2. Estimation. We estimate the remaining structural parameters and the shock processes by fitting the DSGE model to quarterly U.S. time series. The structural parameters to be estimated include the vacancy creation cost parameter $\bar{e}$, the robot adoption cost parameter $\bar{x}$, the habit persistence parameter $\gamma_{c}$, the price adjustment cost parameter $\Omega_{p}$, the dynamic inflation indexation parameter $\gamma_{p}$, and the interest-rate smoothing parameter $\rho_{r}$. In addition, we estimate the parameters of the six shocks in the model: the neutral technology 
shock $Z_{t}$, the automation-specific shock $\zeta_{a t}$, the discount factor shock $\theta_{t}$, the job separation shock $\delta_{t}$, the monetary policy shock $\varepsilon_{r t}$, and the government spending shock $G_{t}$.

III.2.1. Data and measurement. We fit the model to six quarterly time series: the unemployment rate, the job vacancy rate, the growth rate of average labor productivity in the nonfarm business sector, the growth rate of the real wage rate, the inflation rate, and a measure of the nominal interest rate. The sample covers the period from 1985:Q1 to 2018:Q4. ${ }^{12}$

The unemployment rate in the data (denoted by $U_{t}^{\text {data }}$ ) corresponds to the end-of-period unemployment rate in the model $U_{t}$. We demean the unemployment rate data (in log units) and relate it to our model variable according to the measurement equation

$$
\ln \left(U_{t}^{\text {data }}\right)-\ln \left(\bar{U}^{\text {data }}\right)=\hat{U}_{t},
$$

where $\bar{U}^{\text {data }}$ denotes the sample average of the unemployment rate in the data and $\hat{U}_{t}$ denotes the log-deviations of the unemployment rate in the model from its steady-state value.

Similarly, we use demeaned vacancy rate data (also in log units) and relate it to the model variable according to

$$
\ln \left(v_{t}^{\text {data }}\right)-\ln \left(\bar{v}^{\text {data }}\right)=\hat{v}_{t}
$$

where $\bar{v}^{\text {data }}$ denotes the sample average of the vacancy rate data and $\hat{v}_{t}$ denotes the logdeviations of the vacancy rate in the model from its steady-state value. Our vacancy series for the periods prior to 2001 is the vacancy rate constructed by the Help Wanted Index. For the periods after 2001, we use the vacancy rate from JOLTS.

In the data, we measure labor productivity by real output per person in the nonfarm business sector. We use the demeaned quarterly log-growth rate of labor productivity (denoted by $\Delta \ln p_{t}^{d a t a}$ ) and relate it to our model variable according to

$$
\Delta \ln \left(p_{t}^{d a t a}\right)-\Delta \ln \left(p^{d a t a}\right)=\hat{Y}_{t}-\hat{N}_{t}-\left(\widehat{Y}_{t-1}-\widehat{N}_{t-1}\right),
$$

where $\Delta \ln \left(p^{\text {data }}\right)$ denotes the sample average of productivity growth, and $\hat{Y}_{t}$ and $\hat{N}_{t}$ denote the log-deviations of aggregate output and employment from their steady-state levels in our model.

We measure the real wage rate in the data by real compensations per worker in the nonfarm business sector. We relate the observed real wage growth (denoted by $\Delta \ln \left(w_{t}^{\text {data }}\right)$ ) to the model variables by the measurement equation

$$
\Delta \ln \left(w_{t}^{\text {data }}\right)-\Delta \ln \left(w^{\text {data }}\right)=\hat{w}_{t}-\hat{w}_{t-1},
$$

where $\Delta \ln \left(w^{\text {data }}\right)$ denotes the sample average of wage growth in the data and $\hat{w}_{t}$ denotes the log-deviations of real wages from its steady-state level in the model.

\footnotetext{
${ }^{12}$ We present details of these time-series and their sources in Appendix C.
} 
The inflation rate is measured by the quarterly log-growth rate of the personal consumption expenditure price index (PCEPI), taken from the Bureau of Economic Analysis (BEA). The observed inflation rate (denoted by $\pi_{t}^{d a t a}$ ) is related to the model variables by the measurement equation

$$
\pi_{t}^{d a t a}-\pi^{d a t a}=\hat{\pi}_{t}
$$

where $\pi^{\text {data }}$ denotes the sample average of the PCEPI inflation rate in the data and $\hat{\pi}_{t}$ denotes the log-deviation of inflation from its steady-state value in the model.

The nominal interest rate in our model is the return on a one-period risk-free nominal bond, corresponding to the three-month Treasury bills. Our sample covers the post-2008 period, during which U.S. monetary policy was constrained by the zero lower bound (ZLB) on the short-term nominal interest rate. The ZLB presents a computational challenge for estimating the DSGE model based on log-linearized equilibrium conditions. To work around the ZLB issue, we consider the yields on the two-year Treasury notes (denoted by $R_{t}^{(2)}$ ). ${ }^{13}$ Unlike the three-month Treasury bills rate, the two-year Treasury yields did not reach the zero lower bound. More importantly, the use of this longer-term interest rate helps capture the effects of unconventional monetary policy, which is designed to lower yields on longterm securities. To a first-order approximation, the two-year Treasury yields in the data are related to the short-term interest rate in the model by the measurement equation

$$
R_{t}^{(2)}-R^{(2)}=\frac{1}{2} \sum_{j=0}^{7} \hat{R}_{t+j},
$$

where $R^{(2)}$ denotes the sample average of the two-year Treasury yields (annualized), and $\hat{R}_{t}$ denotes the log-deviation of the short-term nominal interest rate in the model from its steady-state value.

III.2.2. Prior distributions and posterior estimates. The prior and posterior distributions of the estimated parameters from our benchmark model are displayed in Table 2.

The priors for the structural parameters $\bar{e}$ and $\bar{x}$ are drawn from the gamma distribution. We assume that the prior mean of each of these three parameters is 5 , with a standard deviation of 1 . The priors for the habit persistence parameter $\gamma_{c}$ is drawn from the beta distribution, with a mean of 0.6 and a standard deviation of 0.1 . The price adjustment cost parameter $\Omega_{p}$ has its priors drawn from the gamma distribution, with a mean of 50 and a standard deviation of 5 . The priors of the inflation indexation parameter $\gamma_{p}$ is drawn from the beta distribution, with a mean of 0.75 and a standard deviation of 0.1 .

\footnotetext{
${ }^{13}$ Swanson and Williams (2014) argue that the Federal Reserve's forward guidance policy typically attempts to influence the two-year Treasury bond yields. Gertler and Karadi (2015) also argue for the use of a long-term interest rate as an indicator of monetary policy in a VAR.
} 
The priors of the persistence parameter of each shock are drawn from the beta distribution with a mean of 0.8 and a standard deviation of 0.1 . The priors of the volatility parameter of each shock are drawn from an inverse gamma distribution with a mean of 0.01 and a standard deviation of 0.1 .

The posterior estimates and the 90 percent probability intervals for the posterior distributions are displayed in the last three columns of Table 2. The posterior mean estimate of the vacancy creation cost parameter is $\bar{e}=2.14$. The posterior mean estimates of the automation cost parameter is $\bar{x}=1.15$. These parameters imply a steady-state share of output produced by automation of $A / Y=0.34$. Thus, our model implies that, in the long run, about 34 percent of the jobs will be performed by robots, which lies in the range of the estimates in the empirical literature (Nedelkoska and Quintini, 2018). The 90 percent probability intervals indicate that the data are informative about the structural parameters.

The price adjustment cost parameter has a posterior mean of $\Omega_{p}=26.86$, with a tight 90 percent probability band. The posterior estimation shows that habit persistence and inflation indexation are not important for our model to match the time-series data. In contrast, these real rigidities and nominal frictions play an important role in generating realistic dynamics in the standard DSGE model without automation and search frictions [e.g., Christiano et al. (2005) and Smets and Wouters (2007)].

The posterior estimation suggests that the shock to neutral technology is highly persistent. The automation-specific shock is less persistent but more volatile than the neutral technology shock. The government spending shock, which captures aggregate demand shocks, is both persistent and volatile. There is also evidence of substantial interest-rate smoothing in the Taylor rule $\left(\rho_{r}=0.87\right)$. The 90 percent probability intervals suggest that the data are informative for all the structural parameters and the shock processes. ${ }^{14}$

\section{Macroeconomic Implications}

We first examine the macroeconomic implications of pandemic-induced decline in labor productivity, which will help contrast the impact of employment uncertainty. For this purpose, we turn on the labor-specific productivity shock $\zeta_{l t}$. We assume that the pandemicinduced labor productivity shock follows the stationary stochastic process

$$
\ln \zeta_{l t}=\left(1-\rho_{l}\right) \ln \bar{\zeta}_{l}+\rho_{l} \ln \zeta_{l, t-1}+\sigma_{l t} \varepsilon_{l t} .
$$

The parameter $\rho_{l} \in(-1,1)$ measures the persistence and the term $\bar{\zeta}_{l}$ is the mean level of the shock. The term $\varepsilon_{l t}$ is an i.i.d. standard normal process.

\footnotetext{
${ }^{14}$ The unconditional forecast variance decompositions are shown in Table A1 and discussed in Appendix D.1.
} 
The term $\sigma_{l t}$ in Eq. (50) is a second-moment shock to the labor-specific technology. It captures the uncertainty in an employment relation, which we call "job uncertainty." The COVID-19 pandemic has led to massive social distancing, both voluntary and mandatory. Many businesses have been closed, leaving millions of workers jobless. Even for those workers who can keep their jobs and work from home, labor productivity has been significantly hampered. Without vaccine or treatment developed, the pandemic could recur, creating substantial uncertainty about future labor productivity. We capture this kind of uncertainty parsimoniously by the second-moment shock to the labor-specific technology, that is $\sigma_{l t}$. The uncertainty shock follows the stationary process

$$
\ln \sigma_{l t}=\left(1-\rho_{\sigma}\right) \ln \bar{\sigma}_{l}+\rho_{\sigma} \ln \sigma_{l, t-1}+\sigma_{\sigma} \varepsilon_{\sigma t}
$$

The parameter $\rho_{\sigma} \in(-1,1)$ is the persistence of the uncertainty shock, the parameter $\bar{\sigma}_{l}>0$ is the mean level of uncertainty, and the term $\sigma_{\sigma}>0$ is the standard deviation of the innovation in the uncertainty shock process. The term $\varepsilon_{\sigma t}$ is an i.i.d. standard normal process.

Since COVID-19 caused economic disruptions only recently, we do not sufficient data for calibrating the parameters in the pandemic-induced shock to workers' productivity. In our baseline model, we calibrate the autocorrelation and the average volatility of the firstmoment shock to be the same as those for the estimated TFP shock. In particular, we set $\rho_{l}=0.9725$ and $\bar{\sigma}_{l}=0.0103$. For the second-moment shock process, we calibrate the persistence parameter to $\rho_{\sigma}=0.95$ and the volatility parameter to $\sigma_{\sigma}=0.01$. We examine alternative calibrations of the persistence of the second-moment shock for robustness.

IV.1. A job uncertainty shock. Figure 2 shows the impulse responses of some key macroeconomic variables following a rise in job uncertainty (i.e., a positive shock to $\sigma_{l t}$ ). As job uncertainty increases, aggregate demand falls, raising unemployment and lowering inflation and the interest rate. The decline in aggregate demand also discourages vacancy creation and posting, reducing the number of vacancies and hiring, and thus further contributing to the rise in unemployment. As labor demand falls, real wages decline.

Facing increased job uncertainty, firms would want to shift the production technology from using workers to using robots. At the same time, the uncertainty shock reduces aggregate demand, and the recessionary effects make it less attractive to adopt robots. Under our calibration, the technology-shifting effect dominates the recessionary effect, leading to an increase in the automation probability when productivity uncertainty rises. The increase in automation allows the firm to produce more output using a given number of workers, improving labor productivity. The improved labor productivity partly mitigates the recessionary effects of the uncertainty shock on unemployment and vacancies. Aggregate output initially 
falls, reflecting weakened aggregate demand from uncertainty, but it eventually rises, driven by the endogenously improved productivity stemming from increased automation.

Figure 3 compares the impulse responses from the benchmark model (the solid blue lines) and those from a counterfactual version of the model without the automation channel (the red dashed lines). The counterfactual is identical to our benchmark model, except that the variables related to automation are kept constant at their steady-state levels. Absent the automation channel, the aggregate demand channel of uncertainty would prevail, leading to a sharper increase in unemployment and a greater decline in inflation than in the benchmark economy. Accordingly, monetary policy responds by cutting the short-term nominal interest rate more aggressively. ${ }^{15}$ In contrast, with the option to automate, firms would have the ability to shift part of the production toward robots when job uncertainty rises; and this technology-shifting effect mitigates the recessionary effects of uncertainty. In our model, the automation mechanism mutes the increase in unemployment (relative to its ergodic mean) by about $1 / 3$ (from 0.72 percent to 0.48 percent); it also dampens the decline in inflation by about about $40 \%$ (from -0.29 percent to -0.17 percent).

There are important interactions between the aggregate demand channel of uncertainty and the automation mechanism. Figure 4 compares the impulse responses in the benchmark model (the blue solid lines) and those from the flexible-price version of the model (red dashed lines). In both the benchmark economy and the flexible-price economy, households would respond to an increase in uncertainty by increasing precautionary savings. All else being equal, precautionary savings reduce the real interest rate, raising the present value of an employment relation and automation and therefore generating expansionary macroeconomic effects. When prices are sticky, as in our benchmark model, the increase in precautionary savings is associated with a reduction in consumption; and the fall in aggregate demand leads to a recession [e.g., Basu and Bundick (2017) and Leduc and Liu (2016)]. If prices are flexible, however, the precautionary saving effect prevails, leading to a boom following the uncertainty shock. As shown in the figure, in the flexible-price version of the model, an increase in job uncertainty reduces unemployment, increases vacancies, and raises the automation probability and labor productivity, leading to an expansion in aggregate output. Thus, in our model, a job uncertainty shock raises potential output but depresses actual output, resulting in a decline in the output gap and inflation. ${ }^{16}$

\footnotetext{
${ }^{15}$ In the no-automation counterfactual (the red dashed lines in the Figure 3), the robot-produced portion of output is constant at the steady state level, such that all variations in aggregate output come from changes in worker-produced output. In response to an uncertainty shock, both output and employment decline, but employment is more sensitive and thus declines by more, resulting in an increase in labor productivity.

${ }^{16}$ Since the pandemic might be recurring, it is possible that agents expect higher uncertainty several quarters in the future but not today. To explore this possibility, we have examined the effects of a news
} 


\section{IV.2. A negative first-moment shock to the level of labor-specific productivity.} We now show that the macroeconomic effects of job uncertainty are markedly different from those of a negative first-moment shock to worker productivity (i.e., a decline in the level of $\left.\zeta_{l t}\right)$.

Figure 5 displays the impulse responses to a negative shock to $\zeta_{l t}$ in our benchmark model. The shock reduces aggregate output, the automation probability, and labor productivity, leading to a recession. Unemployment initially falls, since prices are sticky and firms need to meet demand at the preset prices; the decline in worker productivity requires firms to use more workers for production (Galí, 1999). However, after the initial decline, unemployment rises persistently above its steady-state level. By reducing the level of productivity, the shock leads to an increase in inflation, suggesting that the first-moment shock generates a recession by reducing potential output.

Figure 6 shows the effects of the first-moment shock on potential output. The figure displays the impulse responses following the negative productivity shock in both the benchmark model (the blue solid lines) and the flexible-price version (the red dashed lines). When prices are flexible, output falls persistently following the decline in productivity, and unemployment rises persistently. The automation probability also declines, reinforcing the initial drop in labor productivity.

Overall, although both the uncertainty shock and the negative first-moment productivity shock generate a recession, they work through different mechanisms. Uncertainty shock depresses aggregate demand, leading to a rise in unemployment and a decline in inflation, with the recessionary effects partially offset by the shift of production toward automation. The first-moment shock generates a decline in aggregate activity by reducing potential output, leading to a rise in inflation. Following the first-moment shock, the direct recessionary effects discourage firms from adopting robots, lowering the automation probability and reinforcing the initial decline in labor productivity.

IV.3. Robustness. We consider the robustness of our findings for different parameters in the uncertainty shock process and an alternative approach to modeling automation,.

IV.3.1. Less persistent job uncertainty shocks. In the baseline model, we assume that the pandemic-induced uncertainty shock is very persistent, with an $\operatorname{AR}(1)$ parameter of $\rho_{\sigma}=$ 0.95. Such uncertainty might dissipate more quickly if, for example, a vaccine or treatment is discovered in a short period. This would make the job uncertainty shock less persistent. We now examine the robustness of our results in a scenario with less persistent uncertainty shock to uncertainty in the spirit of Berger et al. (2020a). As we discuss in Appendix D.2, the impulse responses to a news shock to uncertainty are qualitatively similar to those following a contemporaneous shock to uncertainty. 
shocks. In particular, we set the $\mathrm{AR}(1)$ parameter of the uncertainty shock to $\rho_{\sigma}=0.8$ instead of 0.95 .

Figure 7 displays the impulse responses in the baseline model (the blue solid lines) vs. the alternative scenario with less persistent uncertainty (the red dashed lines). If job uncertainty were to dissipate more quickly, then the negative effects on aggregate demand would be dampened, leading to smaller increases in unemployment and smaller declines in inflation and the nominal interest rate. As in the baseline case, the increased job uncertainty stimulates firms' incentive to adopt robots, raising the automation probability despite the declines in aggregate demand. With a less persistent job uncertainty shock, however, the increase in the automation probability becomes more muted. Accordingly, labor productivity increases by less than in the baseline case.

Overall, a less persistent job uncertainty shock produces qualitatively similar impulse responses of the macroeconomic variables, although the effects are smaller in magnitude than in the baseline case.

IV.3.2. Automating jobs instead of vacancies. In our baseline model, we assume that firms can choose to automate an unfilled vacancy if the net benefit of automation is sufficiently high. A plausible alternative setup is to allow firms to automate an existing job instead of an unfilled vacancy. We consider such a framework and show that the main results are robust. We describe the main ingredients in the alternative model here and relegate the details to Appendix E.1.

In the beginning of period $t$, after observing all aggregate shocks, a firm can decide whether or not to replace a worker in an existing job match by a robot. The firm draws a cost $x$ of automation from an i.i.d. distribution $F(x)$ and chooses to automate if the cost lies below the expected benefits of automation. There exists a threshold level of the automation costdenoted by $x_{t}^{*}$-such that the firm automates the job position if and only if $x \leq x_{t}^{*}$. Thus, the automation probability is given by

$$
q_{t}^{a}=F\left(x_{t}^{*}\right)
$$

If the firm adopts a robot, it obtains the automation value $J_{t}^{a}$ (see Eq. (14)) but gives up the employment value $J_{t}^{e}$. Thus, the automation threshold is given by

$$
x_{t}^{*}=J_{t}^{a}-J_{t}^{e}
$$

where the employment value $J_{t}^{e}$ takes into account the possibility of automation, and it satisfies the Bellman equation

$$
J_{t}^{e}=p_{m t} Z_{t} \zeta_{l t}-w_{t}+\mathbb{E}_{t} \beta \theta_{t+1} \frac{\Lambda_{t+1}}{\Lambda_{t}}\left\{\delta_{t+1} J_{t+1}^{v}+\left(1-\delta_{t+1}\right)\left[q_{t+1}^{a} J_{t+1}^{a}+\left(1-q_{t+1}^{a}\right) J_{t+1}^{e}\right]\right\}
$$


A job match yields the flow profit $p_{m t} Z_{t} \zeta_{l t}-w_{t}$ in period $t$. In period $t+1$, the job can be exogenously separated, in which case the firm obtains the vacancy value $J_{t+1}^{v}$. If the job is not separated, it can be automated with the probability $q_{t+1}^{a}$, in which case the firm obtains the automation value $J_{t+1}^{a}$. If the job is neither separated nor automated, then the firm obtains the continuation value of employment $J_{t+1}^{e}$.

Since a fraction of nonseparated jobs are automated, aggregate employment follows the law of motion

$$
N_{t}=\left(1-\delta_{t}\right)\left(1-q_{t}^{a}\right) N_{t-1}+m_{t} .
$$

We summarize the complete set of equilibrium conditions in Appendix E.1. We describe the estimation results in Appendix E.2.

Figure 8 shows the impulse responses following a job uncertainty shock. Similar to what we find in the benchmark model, in this alternative setup where firms have the option to automate an existing job instead of an unfilled vacancy, the uncertainty shock raises unemployment and lowers inflation and the nominal interest rate, suggesting that it leads a decline in aggregate demand, which monetary policy accommodates. In addition, job uncertainty boosts the incentive for firms to use robots to replace workers, increasing the automation probability and labor productivity. Thus, the increase in automation mitigates the recessionary effects of uncertainty, as in our benchmark setup. Under our estimated parameters (see Appendix E.1 for the estimation details), an employment uncertainty shock raises aggregate output, although it also raises unemployment, reflecting the improved labor productivity through automation.

A notable difference from the benchmark model lies in the impulse response of vacancies. In the benchmark model, job uncertainty reduces the number of vacancies, partly reflecting the increase in automation probability (since unfilled vacancies can be automated in the baseline model). Here, firms can automate an existing job instead of a vacancy, and thus automation acts like an endogenous job separation (see Eq. (55)). As before, uncertainty first reduces aggregate demand, discouraging vacancy creation and posting. But at the same time, job uncertainty increases automation, leading to more job separation, and firms respond by posting more vacancies. The aggregate demand effect and the job separation effect work in opposing directions, generating a small initial decline in vacancies and persistent increases in subsequent periods.

\section{Conclusion}

The COVID-19 pandemic has caused massive disruptions of economic activity. It has also raised concerns about the future of work. Absent a quick discovery of vaccines and treatments, workers will remain susceptible to the coronavirus, hindering their ability to work 
and creating uncertainty about worker productivity and the value of employment relations. Such employment uncertainty can boost the incentive for automation, because robots are able to perform contact-intensive and high-risk tasks, but they do not get sick.

We have studied the role of automation in an environment where the pandemic creates job uncertainty. Our New Keynesian DSGE model features endogenous automation decisions and labor market search frictions. We show that the option of automation allows the firm to mitigate the adverse impact of uncertainty about worker productivity. Absent the automation channel, an uncertainty shock would lead to a much deeper recession, with a sharper increase in unemployment and a larger decline in inflation. We also find that uncertainty shocks work through a different channel than a negative shock to the level of labor productivity: uncertainty generates a recession by depressing aggregate demand, whereas a negative productivity shock generates a recession by reducing potential output.

There are a few caveats to our study. By design, our model does not address the direct disruptions to the economy from the pandemic. Our focus is on the business cycle dynamics triggered by the pandemic events. In addition, we do not address the efficacy of policy interventions when job uncertainty increases. Policies such as expanded unemployment insurance benefits or universal basic income have the potential to alleviate the adverse impact of job uncertainty by better insuring income risks and therefore mitigating the decline in aggregate demand. Monetary policy accommodation may also help. Studying these policy issues is an important subject for future research. Our DSGE model provides a useful first step. 
TABLE 1. Calibrated parameters

\begin{tabular}{lll}
\hline \hline & Parameter Description & value \\
\hline$\beta$ & Subjective discount factor & 0.99 \\
$\phi$ & Unemployment benefit & 0.25 \\
$\alpha$ & Elasticity of matching function & 0.50 \\
$\mu$ & Matching efficiency & 0.6606 \\
$\bar{\delta}$ & Job separation rate & 0.10 \\
$\rho^{o}$ & Automation obsolescence rate & 0.03 \\
$\kappa$ & Vacancy posting cost & 0.1068 \\
$b$ & Nash bargaining weight & 0.50 \\
$\eta_{v}$ & Elasticity of vacancy creation cost & 1 \\
$\eta_{a}$ & Elasticity of automation cost & 1 \\
$\kappa_{a}$ & Flow cost of automated production & 0.98 \\
$\chi$ & Disutility of working & 0.9137 \\
$\bar{Z}$ & Mean value of neutral technology shock & 1 \\
$\bar{\zeta}_{l}$ & Mean value of worker-specific productivity & 1 \\
$\bar{\zeta}_{a}$ & Mean value of automation-specific productivity & 1 \\
$\epsilon$ & Elasticity of substitution between differentiated retail goods & 11 \\
$\phi_{\pi}$ & Taylor rule coefficient for inflation & 1.5 \\
$\phi_{u}$ & Taylor rule coefficient for unemployment gap & 0.5 \\
$\frac{G}{Y}$ & Steady-state share of government spending in output & 0.2 \\
\hline
\end{tabular}


TABLE 2. Estimated parameters

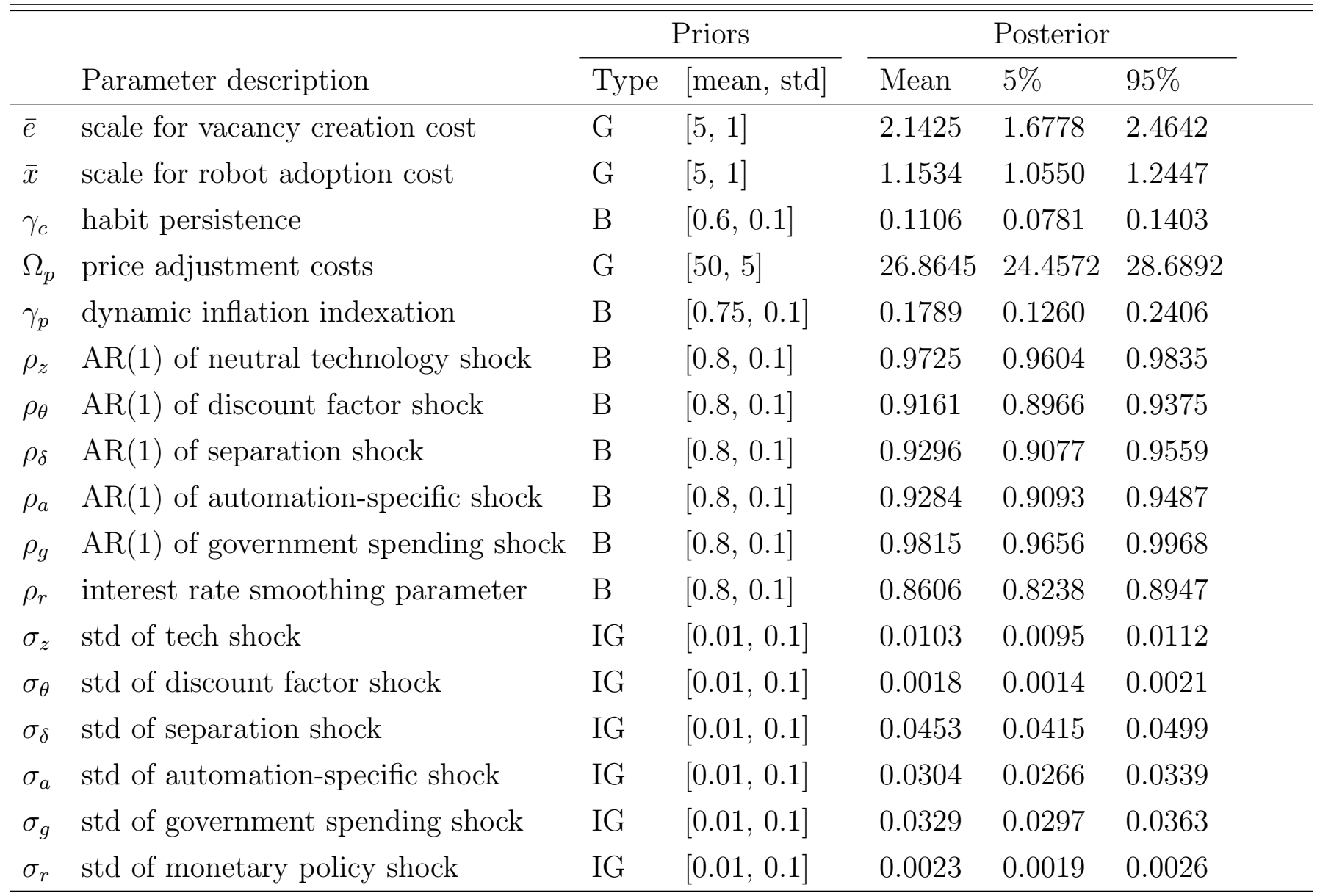

Note: This table shows our baseline estimation results. For the prior distribution types, we use G to denote the gamma distribution, B the beta distribution, and IG the inverse gamma distribution. 


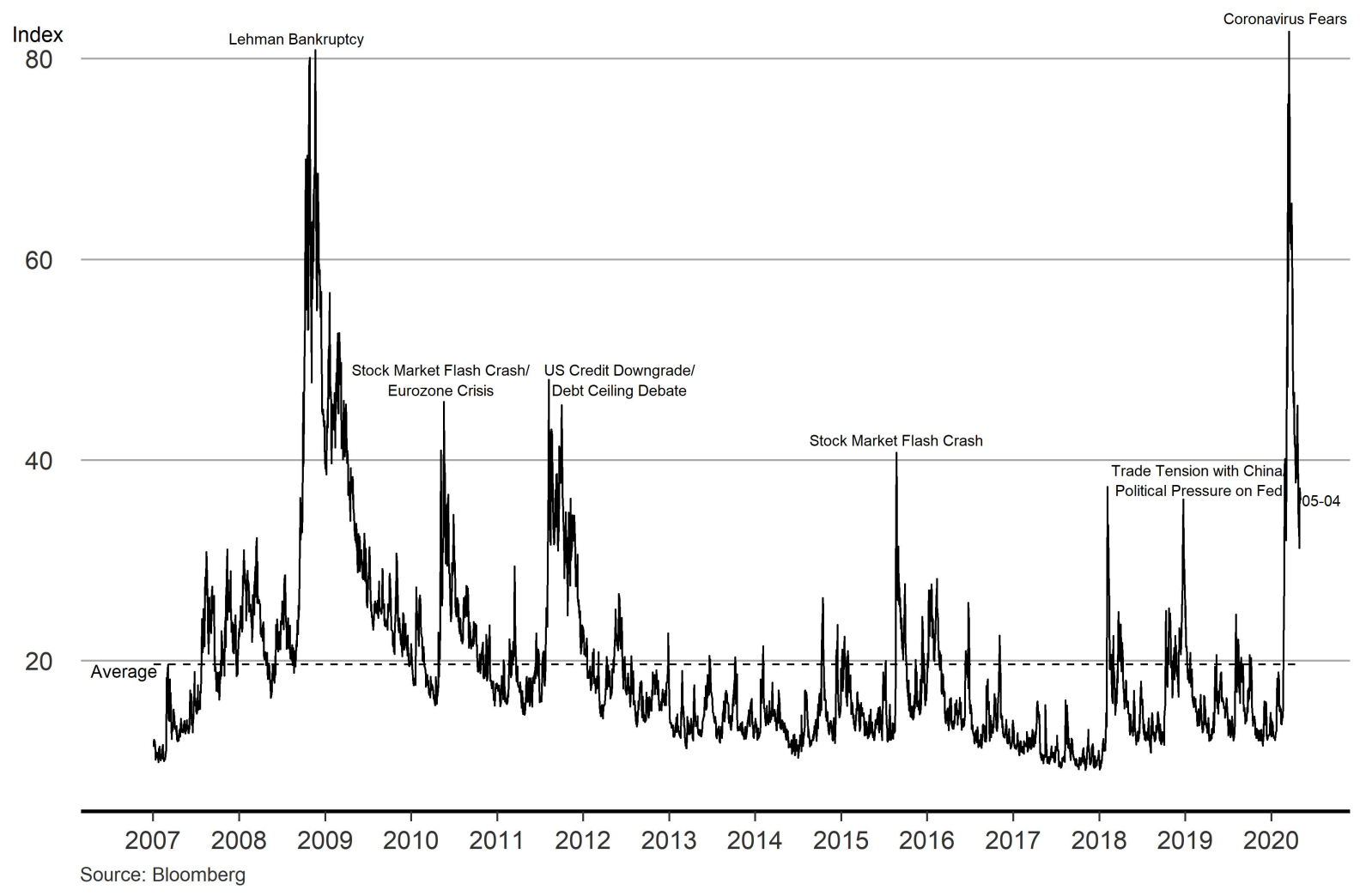

Figure 1. The Chicago Board Options Exchange Volatility Index (VIX): Daily series since 2007 

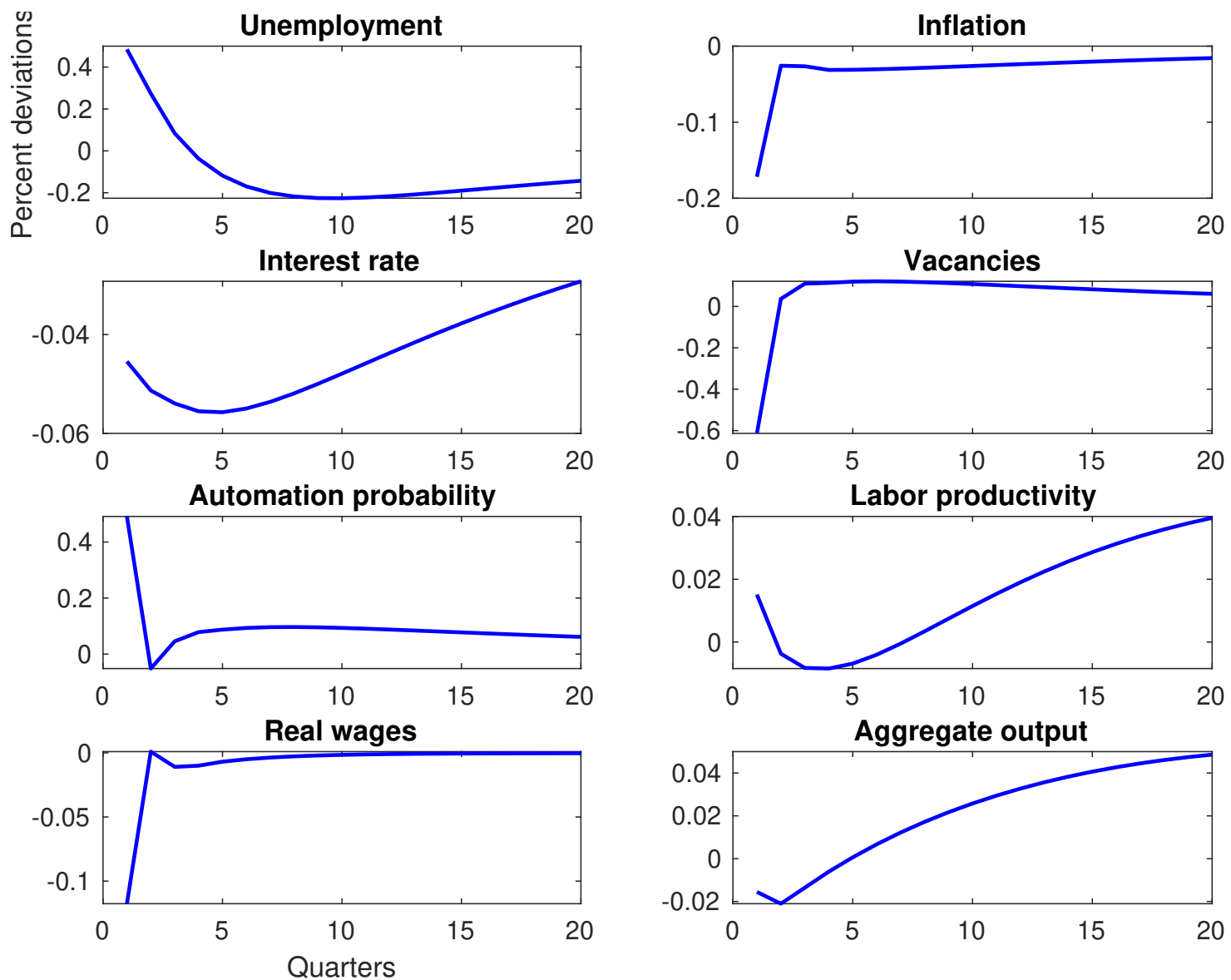

FIGURE 2. Impulse responses to a job uncertainty shock in the benchmark model. 

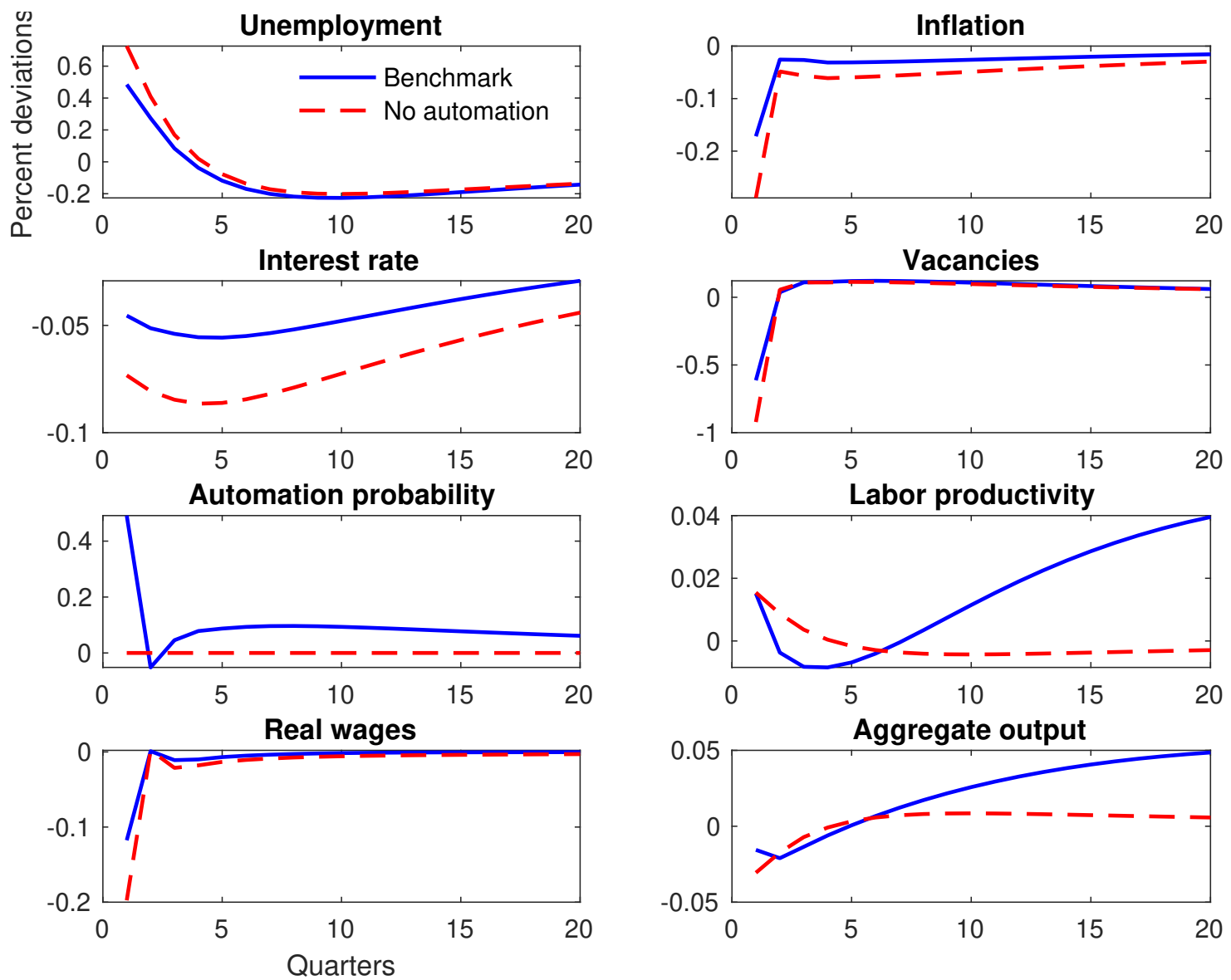

FiguRE 3. Impulse responses to a job uncertainty shock in the benchmark model (blue solid lines) and the counterfactual with no automation (red dashed lines). 

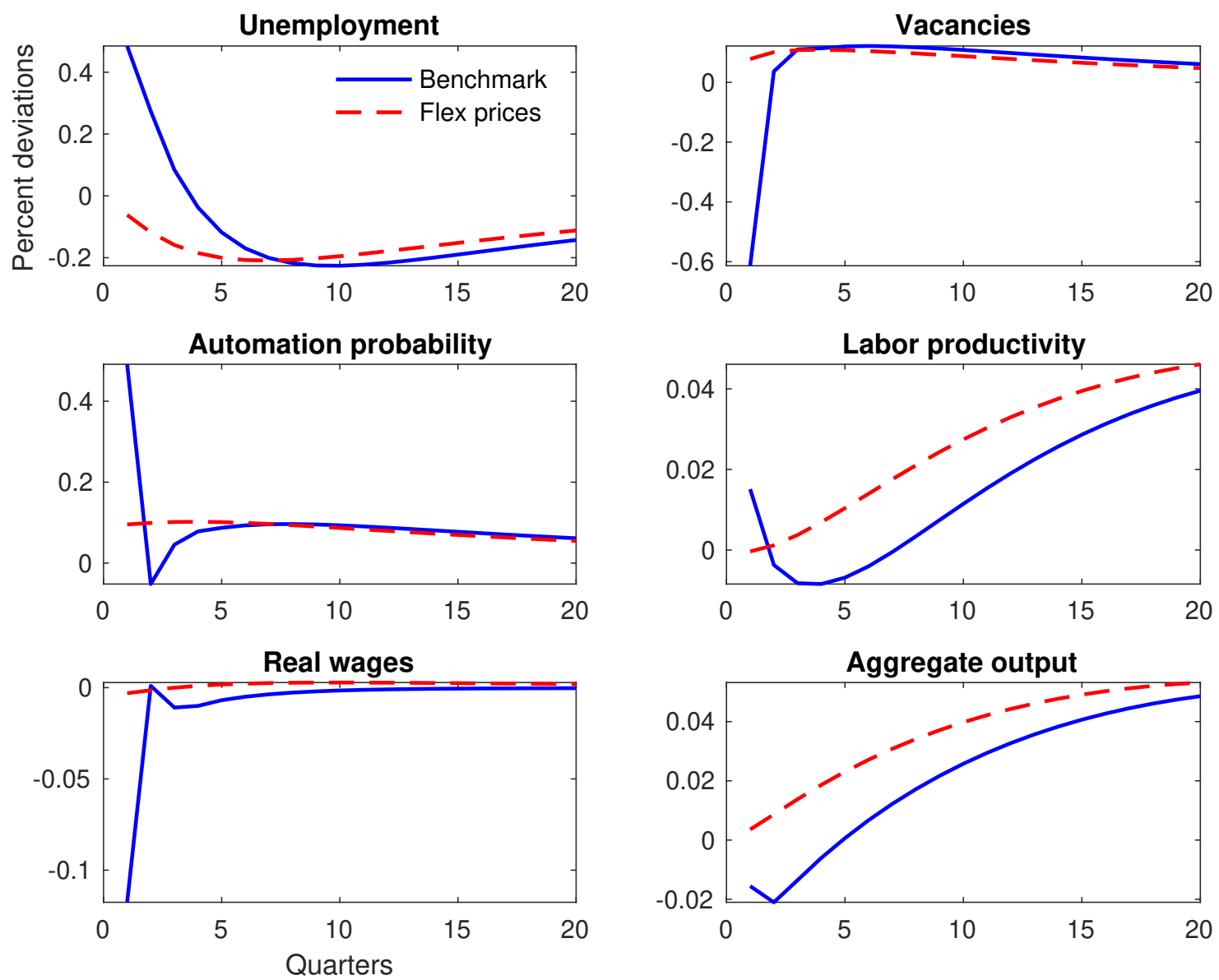

FiguRE 4. Impulse responses to a job uncertainty shock in the benchmark model (blue solid lines) and the flexible-price model (red dashed lines). 

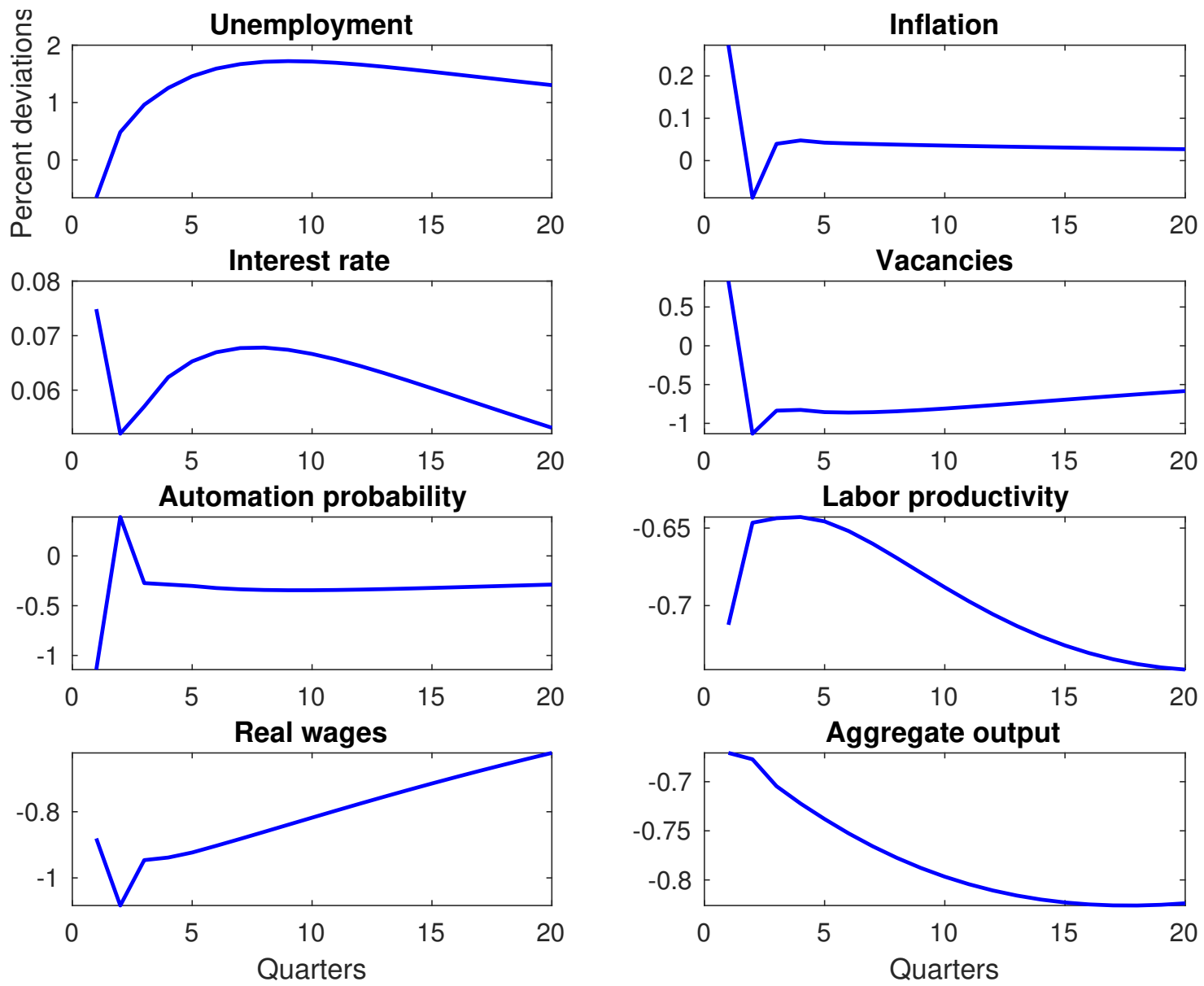

FigURE 5. Impulse responses to a first-moment negative shock to labor productivity in the benchmark model. 

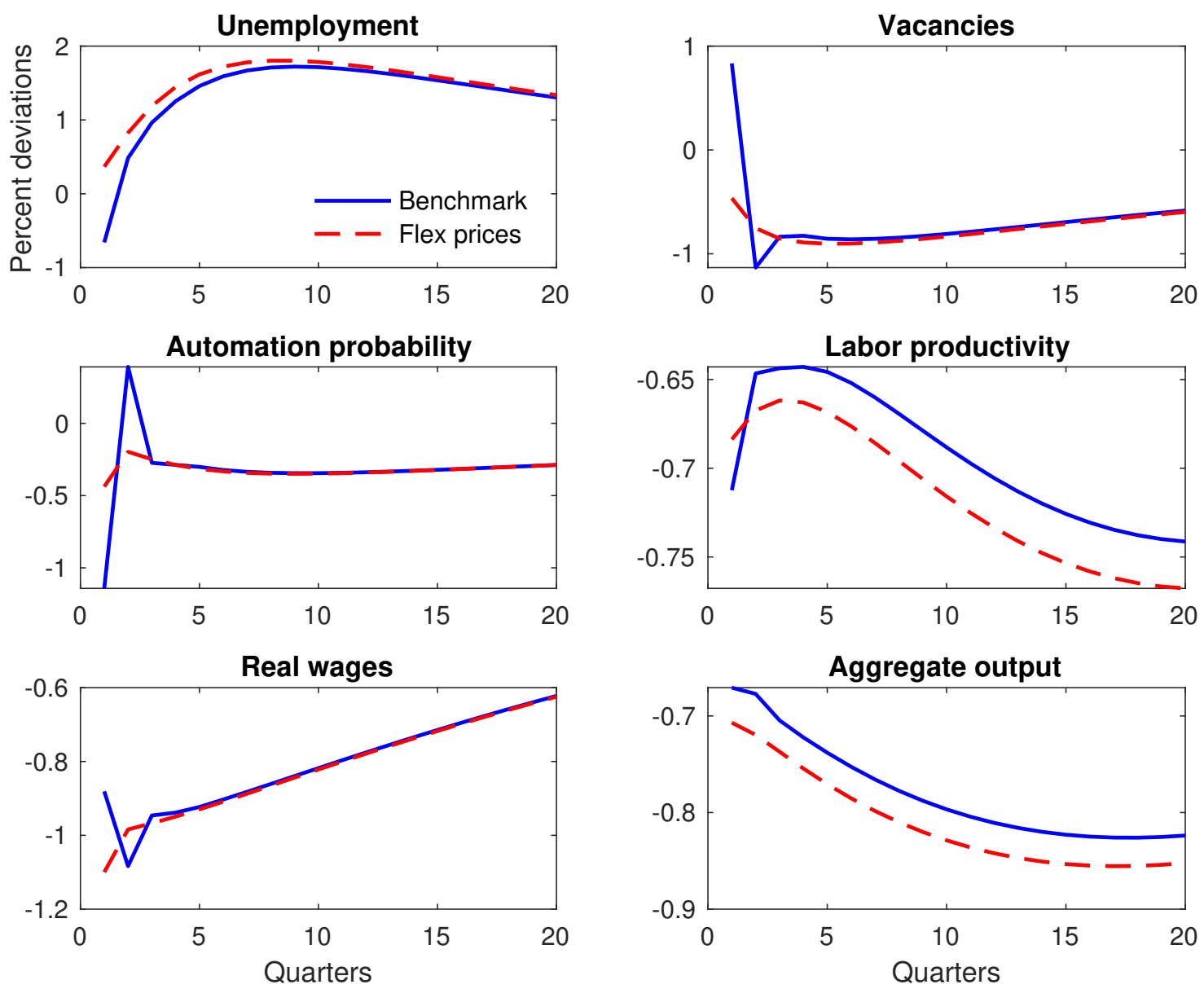

FiguRE 6. Impulse responses to a first-moment negative shock to labor productivity in the benchmark model (blue solid lines) and the flexible-price model (red dashed lines). 

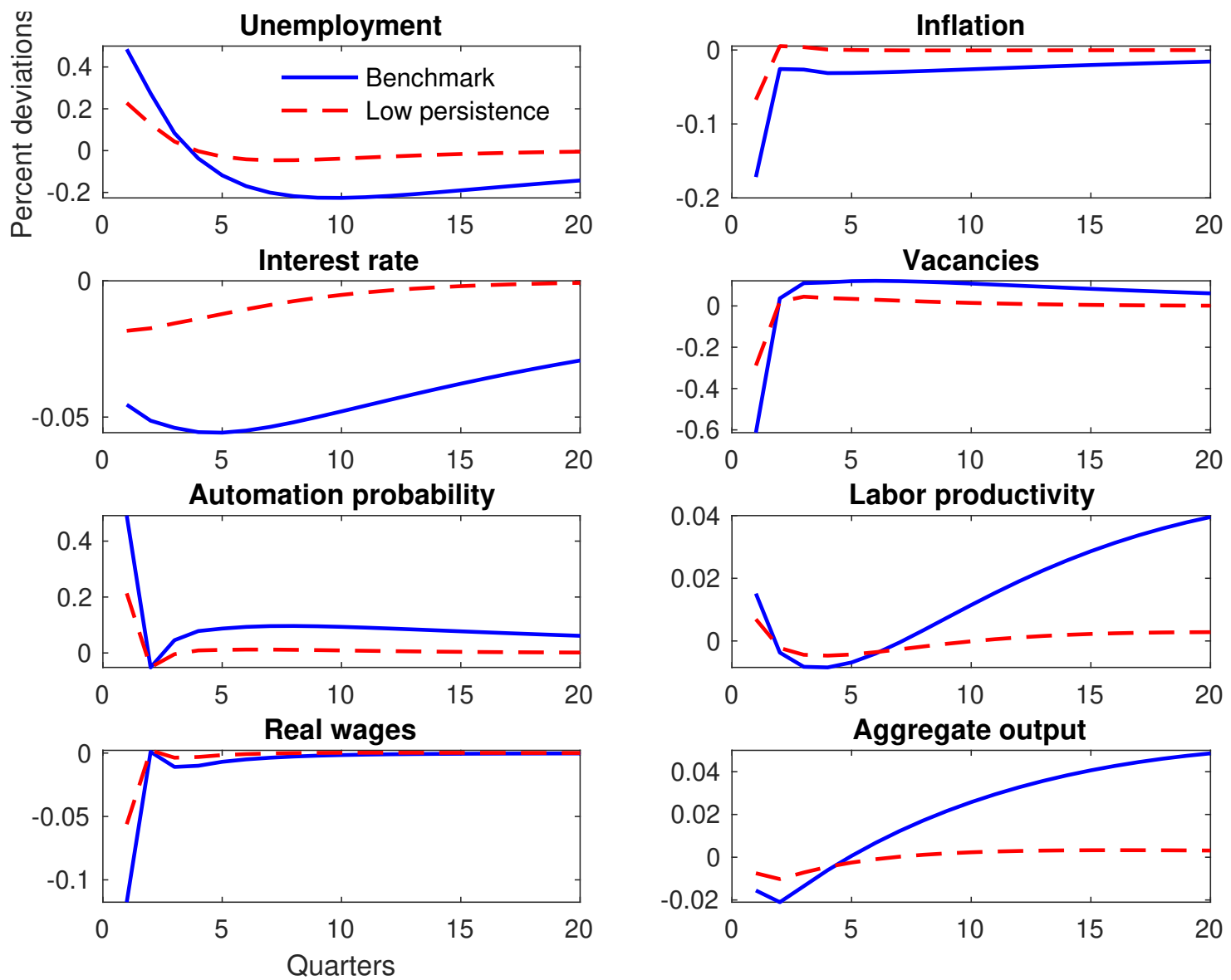

FiguRE 7. Impulse responses to a job uncertainty shock in the benchmark model (blue solid lines) and the alternative scenario with a less persistent job uncertainty shock (red dashed lines). 

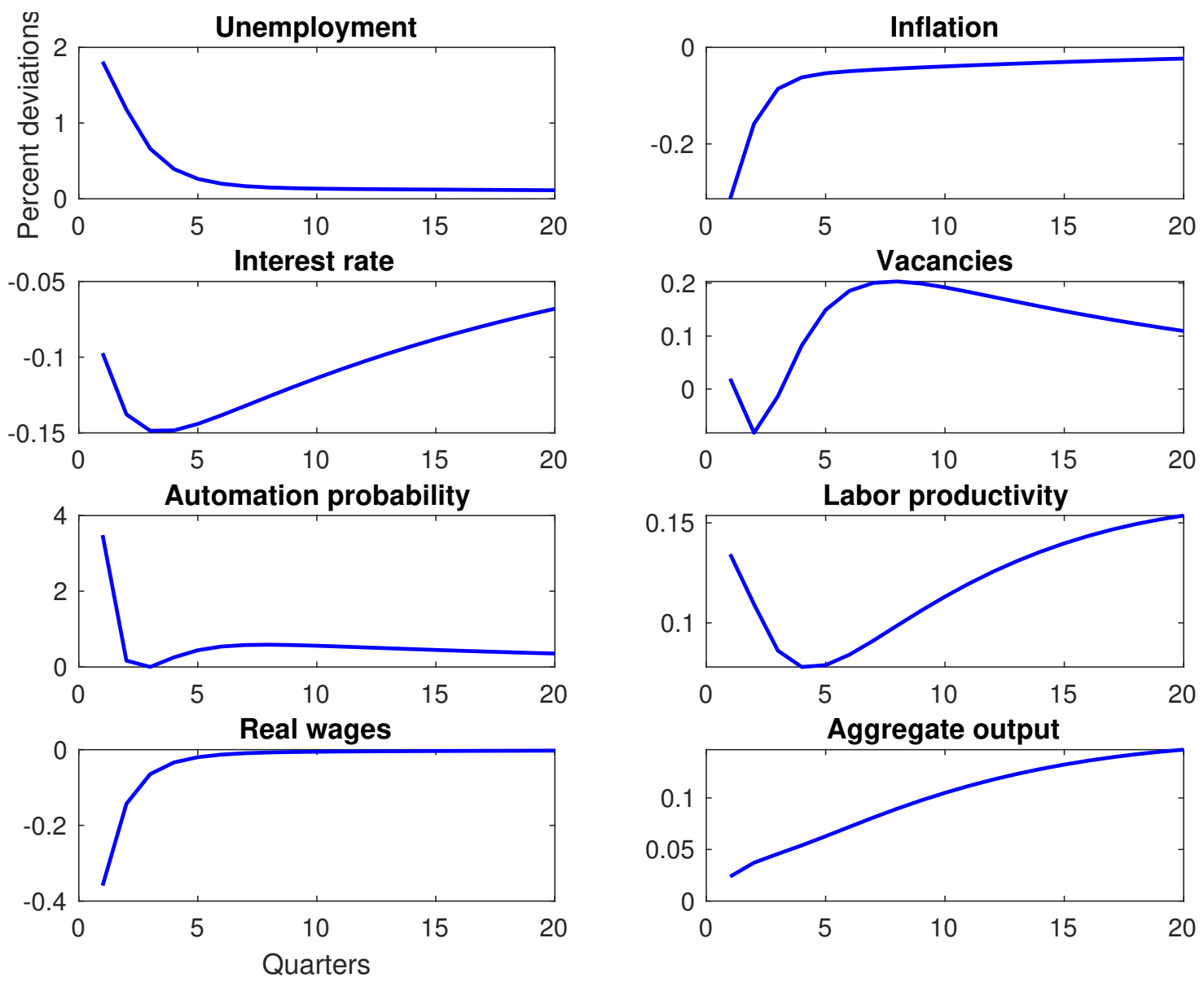

FIGURE 8. Impulse responses to a job uncertainty shock in the alternative setup where firms can automate jobs instead of vacancies. 

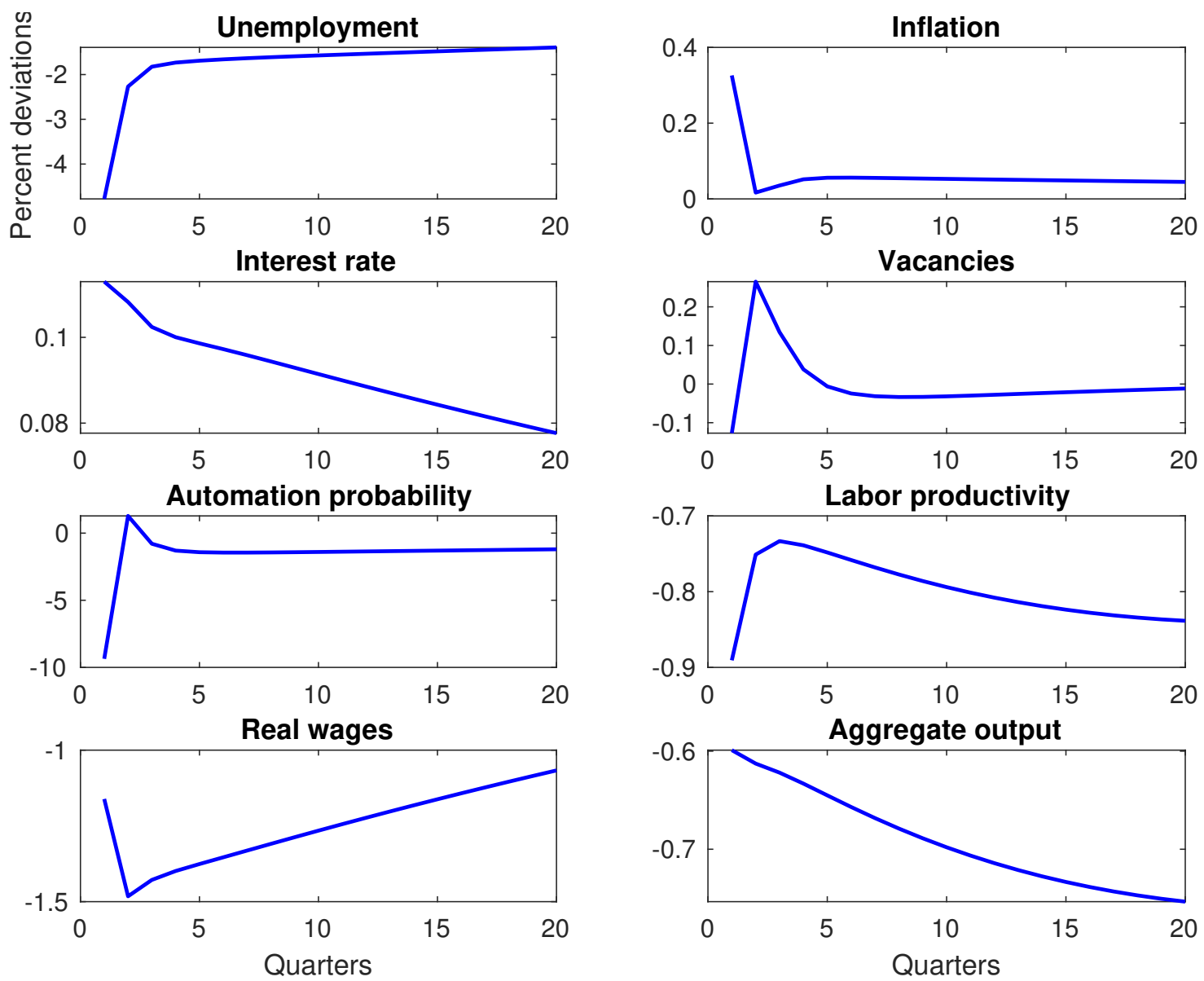

FiguRE 9. Impulse responses to a first-moment negative shock to labor productivity in the alternative setup where firms can automate jobs instead of vacancies. 


\section{ReFERENCES}

Acemoglu, D. And P. Restrepo (2017): "Robots and Jobs: Evidence from US Labor Markets," NBER Working Paper No. 23285.

(2018): "The Race between Man and Machine: Implications of Technology for Growth, Factor Shares, and Employment," American Economic Review, 108, 1488-1542.

Atkeson, A. G. (2020): "What Will Be the Economic Impact of COVID-19 in the US? Rough Estimates of Disease Scenarios," Federal Reserve Bank of Minneapolis Staff Report No. 595.

Autor, D. H. (2015): "Why Are There Still So Many Jobs? The History and Future of Workplace Automation," Journal of Economic Perspectives, 29, 3-30.

Baker, S. R., N. Bloom, S. J. DAvis, And S. J. Terry (2020): "COVID-Induced Economic Uncertainty," NBER Working Paper No. 26983.

Barnichon, R. (2010): "Building a Composite Help-Wanted Index," Economics Letters, 109, 175-178.

Barro, R. J., J. F. Ursúa, And J. Weng (2020): "The Coronavirus and the Great Influenza Pandemic: Lessons from the 'Spanish Flu' for the Coronavirus's Potential Effects on Mortality and Economic Activity," NBER Working Paper No. 26866.

BAsu, S. And B. Bundick (2017): "Uncertainty Shocks in a Model of Effective Demand," Econometrica, 85, 937-958.

Berger, D., I. Dew-Becker, And S. Giglio (2020a): "Uncertainty Shocks as SecondMoment News Shocks," Review of Economic Studies, 87, 40-76.

Berger, D. W., K. F. Herkenhoff, And S. Mongey (2020b): "An SEIR Infectious Disease Model with Testing and Conditional Quarantine," NBER Working Paper No. 26901.

Blanchard, O. J. And J. Galí (2010): "Labor Markets and Monetary Policy: A New Keynesian Model with Unemployment," American Economic Journal: Macroeconomics, $2,1-30$.

Bloom, N. (2009): "The Impact of Uncertainty Shocks," Econometrica, 77, 623-685.

- (2014): "Fluctuations in Uncertainty," Journal of Economic Perspectives, 28, 153176.

Christiano, L., M. Eichenbaum, and C. Evans (2005): "Nominal Rigidities and the Dynamic Effects of a Shock to Monetary Policy," Journal of Political Economy, 113, 1-45. Chudik, A., M. H. Pesaran, And A. Rebucci (2020): "Voluntary and Mandatory Social Distancing: Evidence on COVID-19 Exposure Rates from Chinese Provinces and Selected Countries," Unpublished manuscript. 
Correia, S., S. Luck, And E. Verner (2020): "Pandemics Depress the Economy, Public Health Interventions Do Not: Evidence from the 1918 Flu," Unpubished Manuscript.

den HaAn, W., L. B. Freund, And P. Rendahl (2020): "Volatile Hiring: Uncertainty in Search and Matching Models," Unpublished manuscript.

Den HaAn, W. J., G. Ramey, and J. Watson (2000): "Job Destruction and Propagation of Shocks," American Economic Review, 90, 482-498.

Dietrich, A. M., K. Kuester, G. J. Müller, and R. S. Schoenle (2020): "News and Uncertainty about COVID-19: Survey Evidence and Short-Run Economic Impact," Federal Reserve Bank of Cleveland, Working Paper No. 20-12. https://doi.org/10.26509/frbcwp-202012.

Eichenbaum, M. S., S. Rebelo, And M. Trabandt (2020): "The Macroeconomics of Epidemics," NBER Working Paper No. 26882.

FAnG, H., L. WANG, AND Y. YAng (2020): "Human Mobility Restrictions and the Spread of the Novel Coronavirus (2019-nCoV) in China," NBER Working Paper No. 26906.

Faria e Castro, M. (2020): "Fiscal Policy during a Pandemic," Federal Reserve Bank of St. Louis Working Paper 2020-006D.

Fernández-Villaverde，J. And P. A. Guerrón-Quintana (2020): "Uncertainty Shocks and Business Cycle Research," NBER Working Paper No. 26768.

GaLí, J. (1999): "Technology, employment, and the business cycle: Do technology shocks explain aggregate fluctuations?" American Economic Review, 89, 249-271.

Garibaldi, P., E. R. Moen, And C. A. Pissarides (2020): "Modelling contacts and transitions in the SIR epidemics model," in COVID Economics, Vetted and Real-Time Papers, ed. by C. Wyplosz, CEPR Press, vol. 5, 1-20.

Gertler, M. And P. Karadi (2015): "Monetary Policy Surprises, Credit Costs, and Economic Activity," American Economic Journal: Macroeconomics, 7, 44-76.

Gertler, M. and A. Trigari (2009): "Unemployment Fluctuations with Staggered Nash Wage Bargaining," Journal of Political Economy, 117, 38-86.

Glover, A., J. Heathcote, D. Krueger, And J.-V. Ríos-Rull (2020): "Health versus Wealth: On the Distributional Effects of Controlling a Pandemic," Federal Reserve Bank of Minneapolis Staff Report No. 600.

Graetz, G. And G. Michaels (2018): "Robots at Work," The Review of Economics and Statistics, 107, 753-768.

Guerrieri, V., G. Lorenzoni, L. Straub, and I. Werning (2020): "Macroeconomic Implications of COVID-19: Can Negative Supply Shocks Cause Demand Shortages?" Unpublished manuscript. 
Hall, R. E. And P. R. Milgrom (2008): "The Limited Influence of Unemployment on the Wage Bargain," American Economic Review, 98, 1653-1674.

He, H. AND Z. Liu (2008): "Investment-Specific Technological Change, Skill Accumulation, and Wage Inequality," Review of Economic Dynamics, 11, 314-334.

Hershbein, B. And L. B. Kahn (2018): "Do Recessions Accelerate Routine- Biased Technological Change? Evidence from Vacancy Postings," American Economic Review, 108, 1737-1772.

Jaimovich, N., I. Saporta-Eksten, H. Siu, And Y. Yedid-Levi (2020): "The Macroeconomics of Automation: Data, Theory, and Policy Analysis," Unfinished Manuscript.

Jaimovich, N. And H. E. Siu (2018): “Job Polarization and Jobless Recoveries," Unpubished Manuscript.

Jones, C. J., T. Philippon, And V. Venkateswaran (2020): "Optimal Mitigation Policies in a Pandemic: Social Distancing and Working from Home," NBER Working Paper No. 26984.

Jorda, O., S. R. Singh, And A. M. TAylor (2020): "Longer-Run Economic Consequences of Pandemics," Federal Reserve Bank of San Francisco Working Paper 2020-09.

Kermack, W. O. And A. G. MCKendrick (1927): "A Contribution to the Mathematical Theory of Epidemics," Proceedings of the Royal Society of London, A115, 700-721.

Krusell, P., L. E. Ohanian, J. V. Ríos-Rull, and G. L. Violante (2000): "CapitalSkill Complementarity and Inequality: A Macroeconomic Analysis," Econometrica, 68, 1029-1053.

LEDUC, S. AND Z. LiU (2016): "Uncertainty Shocks Are Aggregate Demand Shocks," Journal of Monetary Economics, 82, 20-35.

- (2019): "Robots or Workers? A Macro Analysis of Automation and Labor Markets," Federal Reserve Bank of San Francisco Working Paper No. 2019-17.

- (2020a): "The Uncertainty Channel of the Coronavirus," FRBSF Economic Letter, 2020-07, 1-4.

(2020b): "The Weak Job Recovery in a Macro Model of Search and Recruiting Intensity," American Economic Journal: Macroeconomics, 12, 310-343.

Ma, C., J. Rogers, And S. Zhou (2020): "Global Economic and Financial Effects of 21st Century Pandemics and Epidemics," Unpublished Manuscript.

Nedelkoska, L. And G. Quintini (2018): "Automation, Skills Use and Training," OECD Social, Employment and Migration Working Papers, No. 202.

Rotemberg, J. J. (1982): "Sticky Prices in the United States," Journal of Political Economy, $90,1187-1211$. 
Smets, F. And R. Wouters (2007): "Shocks and Frictions in US Business Cycles: A Bayesian DSGE Approach," American Economic Review, 97, 586-606.

Swanson, E. T. and J. C. Williams (2014): "Measuring the Effect of the Zero Lower Bound on Medium- and Longer-Term Interest Rates," American Economic Review, 104, 3154-3185.

ZeirA, J. (1998): "Workers, Machines, and Economic Growth," Quarterly Journal of Economics, 113, 1091-1117. 


\section{Appendix A. Derivations of household's optimizing Conditions}

Denote by $V_{t}\left(B_{t-1}, N_{t-1}\right)$ the value function for the representative household. The household's optimizing problem can be written in the recursive form

$$
V_{t}\left(B_{t-1}, N_{t-1}\right) \equiv \max \ln \left(C_{t}-\gamma_{c} C_{t-1}\right)-\chi N_{t}+\beta \mathbb{E}_{t} \theta_{t+1} V_{t+1}\left(B_{t}, N_{t}\right),
$$

subject to the budget constraint

$$
C_{t}+\frac{B_{t}}{r_{t}}=B_{t-1}+w_{t} N_{t}+\phi\left(1-N_{t}\right)+d_{t}-T_{t},
$$

and the law of motion for employment

$$
N_{t}=\left(1-\delta_{t}\right) N_{t-1}+q_{t}^{u} u_{t},
$$

where the measure of job seekers is given by

$$
u_{t}=1-\left(1-\delta_{t}\right) N_{t-1} .
$$

The household chooses $C_{t}, B_{t}$, and $N_{t}$, taking prices and the average job finding rate as given.

Denote by $\Lambda_{t}$ the Lagrangian multiplier for the budget constraint (A2). The first-order condition with respect to consumption implies that

$$
\Lambda_{t}=\frac{1}{C_{t}-\gamma_{c} C_{t-1}}-\mathbb{E}_{t} \frac{\beta \theta_{t+1} \gamma_{c}}{C_{t+1}-\gamma_{c} C_{t}} .
$$

The optimizing decision for $B_{t}$ implies that

$$
\frac{\Lambda_{t}}{r_{t}}=\beta \mathrm{E}_{t} \theta_{t+1} \frac{\partial V_{t+1}\left(B_{t}, N_{t}\right)}{\partial B_{t}} .
$$

The envelope condition with respect to $B_{t-1}$ implies that

$$
\frac{\partial V_{t}\left(B_{t-1}, N_{t-1}\right)}{\partial B_{t-1}}=\Lambda_{t} .
$$

We thus obtain the intertemporal Euler equation

$$
1=\mathrm{E}_{t} \frac{\beta \theta_{t+1} \Lambda_{t+1}}{\Lambda_{t}} r_{t}
$$

which is equation (25) in the text.

The envelope condition with respect to $N_{t-1}$ implies that

$$
\frac{\partial V_{t}\left(B_{t-1}, N_{t-1}\right)}{\partial N_{t-1}}=\left[\Lambda_{t}\left(w_{t}-\phi\right)-\chi+\beta \mathrm{E}_{t} \theta_{t+1} \frac{\partial V_{t+1}\left(B_{t}, N_{t}\right)}{\partial N_{t}}\right] \frac{\partial N_{t}}{\partial N_{t-1}} .
$$

Equations (A3) and (A4) imply that

$$
\frac{\partial N_{t}}{\partial N_{t-1}}=\left(1-\delta_{t}\right)\left(1-q_{t}^{u}\right)
$$


and that

$$
\frac{\partial u_{t}}{\partial N_{t-1}}=-\left(1-\delta_{t}\right)
$$

Define the employment surplus (i.e., the value of employment relative to unemployment) as

$S_{t}^{H}=\frac{1}{\Lambda_{t}} \frac{\partial V_{t}\left(B_{t-1}, N_{t-1}\right)}{\partial N_{t}}=\frac{1}{\Lambda_{t}} \frac{\partial V_{t}\left(B_{t-1}, N_{t-1}\right)}{\partial N_{t-1}} \frac{\partial N_{t-1}}{\partial N_{t}}=\frac{1}{\Lambda_{t}} \frac{\partial V_{t}\left(B_{t-1}, N_{t-1}\right)}{\partial N_{t-1}} \frac{1}{\left(1-\delta_{t}\right)\left(1-q^{u}\left(s_{t}\right)\right)}$.

Thus, $S_{t}^{H}$ is the value for the household to send an additional worker to work in period $t$. Then the envelope condition (A9) implies that

$$
S_{t}^{H}=w_{t}-\phi-\frac{\chi}{\Lambda_{t}}+\mathrm{E}_{t} \frac{\beta \theta_{t+1} \Lambda_{t+1}}{\Lambda_{t}}\left(1-\delta_{t+1}\right)\left(1-q_{t+1}^{u}\right) S_{t+1}^{H} .
$$

The employment surplus $S_{t}^{H}$ derived here corresponds to equation (24) in the text, and it is the relevant surplus for the household in the Nash bargaining problem.

\section{Appendix B. Summary of Equilibrium CONDItions}

A search equilibrium is a system of 21 equations for 21 variables summarized in the vector

$$
\left[C_{t}, R_{t}, \pi_{t}, p_{m t}, Y_{t}, m_{t}, u_{t}, v_{t}, q_{t}^{u}, q_{t}^{v}, q_{t}^{a}, N_{t}, U_{t}, \eta_{t}, J_{t}^{e}, J_{t}^{v}, J_{t}^{a}, w_{t}, A_{t}, x_{t}^{*}, \Lambda_{t}\right]
$$

We write the equations in the same order as in the dynare code.

(1) Household marginal utility of consumption:

$$
\Lambda_{t}=\frac{1}{C_{t}-\gamma_{c} C_{t-1}}-\mathbb{E}_{t} \frac{\beta \theta_{t+1} \gamma_{c}}{C_{t+1}-\gamma_{c} C_{t}}
$$

(2) Household's bond Euler equation:

$$
1=\mathrm{E}_{t} \beta \theta_{t+1} \frac{\Lambda_{t+1}}{\Lambda_{t}} \frac{R_{t}}{\pi_{t+1}},
$$

(3) Matching function

$$
m_{t}=\mu u_{t}^{\alpha} v_{t}^{1-\alpha},
$$

(4) Job finding rate

$$
q_{t}^{u}=\frac{m_{t}}{u_{t}}
$$

(5) Vacancy filling rate

$$
q_{t}^{v}=\frac{m_{t}}{v_{t}}
$$

(6) Employment dynamics

$$
N_{t}=\left(1-\delta_{t}\right) N_{t-1}+m_{t},
$$

(7) Number of searching workers

$$
u_{t}=1-\left(1-\delta_{t}\right) N_{t-1},
$$


(8) Unemployment

$$
U_{t}=1-N_{t},
$$

(9) Vacancy dynamics

$$
v_{t}=\left(1-q_{t-1}^{v}\right)\left(1-q_{t}^{a}\right) v_{t-1}+\delta_{t} N_{t-1}+\eta_{t},
$$

(10) Automation dynamics

$$
A_{t}=\left(1-\rho^{o}\right) A_{t-1}+\left(1-q_{t-1}^{v}\right) q_{t}^{a} v_{t-1},
$$

(11) Automation value

$$
J_{t}^{a}=p_{m t} Z_{t} \zeta_{a t}\left(1-\kappa_{a}\right)+\left(1-\rho^{o}\right) \mathbb{E}_{t} \beta \theta_{t+1} \frac{\Lambda_{t+1}}{\Lambda_{t}} J_{t+1}^{a},
$$

(12) Vacancy value

$$
J_{t}^{v}=-\kappa+q_{t}^{v} J_{t}^{e}+\left(1-q_{t}^{v}\right) \mathbb{E}_{t} \beta \theta_{t+1} \frac{\Lambda_{t+1}}{\Lambda_{t}}\left[\left(1-q_{t+1}^{a}\right) J_{t+1}^{v}+q_{t+1}^{a} J_{t+1}^{a}\right] .
$$

(13) Employment value

$$
J_{t}^{e}=p_{m t} Z_{t} \zeta_{l t}-w_{t}+\mathbb{E}_{t} \beta \theta_{t+1} \frac{\Lambda_{t+1}}{\Lambda_{t}}\left\{\left(1-\delta_{t+1}\right) J_{t+1}^{e}+\delta_{t+1} J_{t+1}^{v}\right\},
$$

(14) Automation threshold

$$
x_{t}^{*}=J_{t}^{a}-J_{t}^{v},
$$

(15) Robot adoption

$$
q_{t}^{a}=\left(\frac{x_{t}^{*}}{\bar{x}}\right)^{\eta_{a}}
$$

(16) Vacancy creation

$$
\eta_{t}=\left(\frac{J_{t}^{v}}{\bar{e}}\right)^{\eta_{e}}
$$

(17) Aggregate output

$$
Y_{t}=Z_{t} \zeta_{l t} N_{t}+Z_{t} \zeta_{a t} A_{t}
$$

(18) Resource constraint

$$
\begin{aligned}
Y_{t} & =C_{t}+G_{t}+\kappa v_{t}+\kappa_{a} Z_{t} \zeta_{a t} A_{t}+\frac{\eta_{a}}{1+\eta_{a}} q_{t}^{a} x_{t}^{*}\left(1-q_{t-1}^{v}\right) v_{t-1}+\frac{\eta_{e}}{1+\eta_{e}} \eta_{t} J_{t}^{v} \\
& +\frac{\Omega_{p}}{2}\left(\frac{\pi_{t}}{\pi_{t-1}^{\gamma_{p}} \pi^{1-\gamma_{p}}}-1\right)^{2} Y_{t}
\end{aligned}
$$

(19) Nash bargaining wage

$\frac{b}{1-b}\left(J_{t}^{e}-J_{t}^{v}\right)=w_{t}-\phi-\frac{\chi}{\Lambda_{t}}+\mathbb{E}_{t} \beta \theta_{t+1} \frac{\Lambda_{t+1}}{\Lambda_{t}}\left(1-q_{t+1}^{u}\right)\left(1-\delta_{t+1}\right) \frac{b}{1-b}\left(J_{t+1}^{e}-J_{t+1}^{v}\right)$, 
(20) With dynamic inflation indexation, the Phillips curve is given by

$p_{m t}=\frac{\epsilon-1}{\epsilon}+\frac{\Omega_{p}}{\epsilon}\left[\frac{\pi_{t}}{\pi_{t-1}^{\gamma_{p}} \pi^{1-\gamma_{p}}}\left(\frac{\pi_{t}}{\pi_{t-1}^{\gamma_{p}} \pi^{1-\gamma_{p}}}-1\right)-E_{t} \frac{\beta \theta_{t+1} \Lambda_{t+i}}{\Lambda_{t}} \frac{Y_{t+1}}{Y_{t}} \frac{\pi_{t+1}}{\pi_{t}^{\gamma_{p}} \pi^{1-\gamma_{p}}}\left(\frac{\pi_{t+1}}{\pi_{t}^{\gamma_{p}} \pi^{1-\gamma_{p}}}-1\right)\right]$

where $\gamma_{p}$ measures the importance of dynamic indexation.

(21) Taylor rule

$$
\frac{R_{t}}{R}=\left(\frac{R_{t-1}}{R}\right)^{\rho_{r}}\left[\left(\frac{\pi_{t}}{\pi}\right)^{\phi_{\pi}}\left(\frac{U_{t}}{U_{t}^{*}}\right)^{-\frac{\phi_{u}}{4}}\right]^{1-\rho_{r}} \exp \left(\varepsilon_{r t}\right) .
$$

Appendix C. Data

We fit the DSGE model to six quarterly U.S. time series: the unemployment rate, the job vacancy rate, real wage growth, labor productivity growth, inflation, and a measure of the nominal interest rate. The sample covers the period from 1985:Q1 to 2018:Q4.

(1) Unemployment: Civilian unemployment rate (16 years and over) from the Bureau of Labor Statistics, seasonally adjusted monthly series (LRUSECON in Haver).

(2) Job vacancies: For pre-2001 periods, we use the vacancy rate constructed by Barnichon (2010) based on the Help Wanted Index. For the periods starting in 2001, we use the job openings from the Job Openings and Labor Turnover Survey (JOLTS), seasonally adjusted monthly series (LIJTLA@USECON in Haver).

(3) Real wages: real compensation per worker in the nonfarm business sector. We first compute the nominal wage rate as the ratio of nonfarm business compensation for all persons (LXNFF@USECON in Haver) to nonfarm business employment (LXNFM@USECON) and then deflate it using the nonfarm business sector implicit price deflator (LXNFI@USECON).

(4) Labor productivity: nonfarm business sector real output per person (LXNFS@USECON in Haver).

(5) Inflation: Quarterly log-growth rates of the personal consumption expenditure chain price index (JCM@USNA in Haver, seasonally adjusted and annualized).

(6) Nominal interest rate: Two-year Treasury note yields at constant maturity (FCM2@USECON in Haver, annualized).

\section{Appendix D. Additional quantitative results}

D.1. Forecast error variance decompositions from the estimation. Table A1 shows the forecast error variance decomposition results from the estimated model. Most fluctuations in unemployment and vacancies are driven by aggregate demand shocks (government spending shocks). Job separation shocks and the neutral technology shocks together account for about 20 percent of the vacancy fluctuations. The variance of productivity growth 
TABLE A1. Forecasting Error Variance Decomposition

\begin{tabular}{lcccccc}
\hline \hline Variables & $\begin{array}{c}\text { Neutral } \\
\text { technology }\end{array}$ & $\begin{array}{c}\text { Discount } \\
\text { factor }\end{array}$ & $\begin{array}{c}\text { Job } \\
\text { separation }\end{array}$ & $\begin{array}{c}\text { Automation- } \\
\text { specific }\end{array}$ & $\begin{array}{c}\text { Government } \\
\text { spending }\end{array}$ & $\begin{array}{c}\text { Monetary } \\
\text { policy }\end{array}$ \\
\hline Unemployment & 9.01 & 1.58 & 0.43 & 0.99 & 87.88 & 0.11 \\
Vacancy & 7.74 & 1.46 & 12.37 & 0.87 & 77.30 & 0.27 \\
Productivity growth & 35.91 & 0.71 & 0.82 & 50.15 & 12.15 & 0.26 \\
Real wage growth & 47.68 & 14.71 & 0.14 & 0.04 & 13.90 & 23.53 \\
Inflation & 11.74 & 24.43 & 0.38 & 0.24 & 29.81 & 33.41 \\
Two-year Treasury & 36.53 & 55.08 & 0.87 & 0.52 & 6.18 & 0.82 \\
\hline \hline
\end{tabular}

Note: The numbers reported are the posterior mean contributions (in percentage terms) of each shock to the forecast error variances of the variables listed in the rows.

is mainly accounted for by the neutral technology shock and the automation-specific technology shock. Real wage growth is driven by the two technology shocks as well as the shocks to monetary policy and government spending. Inflation fluctuations in our model are driven by the three types of demand shocks: discount factor, government spending, and monetary policy. Fluctuations in the observed two-year Treasury notes are driven mainly by the discount factor shocks and, to a lesser extent, the neutral technology shock.

D.2. News shocks to productivity uncertainty. We have also examined the macro effects of news shocks to employment uncertainty. In particular, we generalize the stochastic process of the second-moment shock to labor-specific productivity in Eq (51) to include a news component:

$$
\ln \sigma_{l t}=\left(1-\rho_{\sigma}\right) \ln \bar{\sigma}_{l}+\rho_{\sigma} \ln \sigma_{l, t-1}+\sigma_{\sigma} \varepsilon_{\sigma t}+\sigma_{\nu} \varepsilon_{\nu t-4},
$$

where $\varepsilon_{\nu t-4}$ is an i.i.d. standard normal process that captures news shocks to the uncertainty four quarters ahead, and $\sigma_{\nu}$ is the standard deviation of the news shock.

Figure A1 displays the impulse responses following a positive news shock to job uncertainty. The qualitative (and quantitative) effects of the news shock to uncertainty are broadly similar to those of the contemporaneous uncertainty shock shown in Figure 2. In particular, the shock reduces aggregate demand and therefore pushes up unemployment and pushes down inflation and the nominal interest rate. It reduces vacancies as well. Firms respond to the news shock to uncertainty by shifting technologies toward more automation, raising the automation probability, boosting labor productivity, and therefore partially mitigating the recessionary effects of the news shock to uncertainty. 
In the counterfactual case with no fluctuations in automation, Figure A2 shows that unemployment would have risen more sharply and inflation would have fallen more sharply (see the red dashed lines). In this counterfactual environment, firms do not have the option of automating production when worker productivity uncertainty is expected to rise. In this case, automation cannot be used to mitigate the decline in aggregate demand caused by the expected rise in uncertainty.

Similar to the case with contemporaneous uncertainty shocks to worker productivity, Figure A3 shows that news of job uncertainty has expansionary effects when prices are flexible (see the red dashed lines). With flexible prices, the aggregate demand channel is shut off, and precautionary savings by the households reduces the real interest rate, boosting the present value of automation and employment, leading to increases in hiring workers and adopting robots, despite that the two technologies are perfect substitutes. 

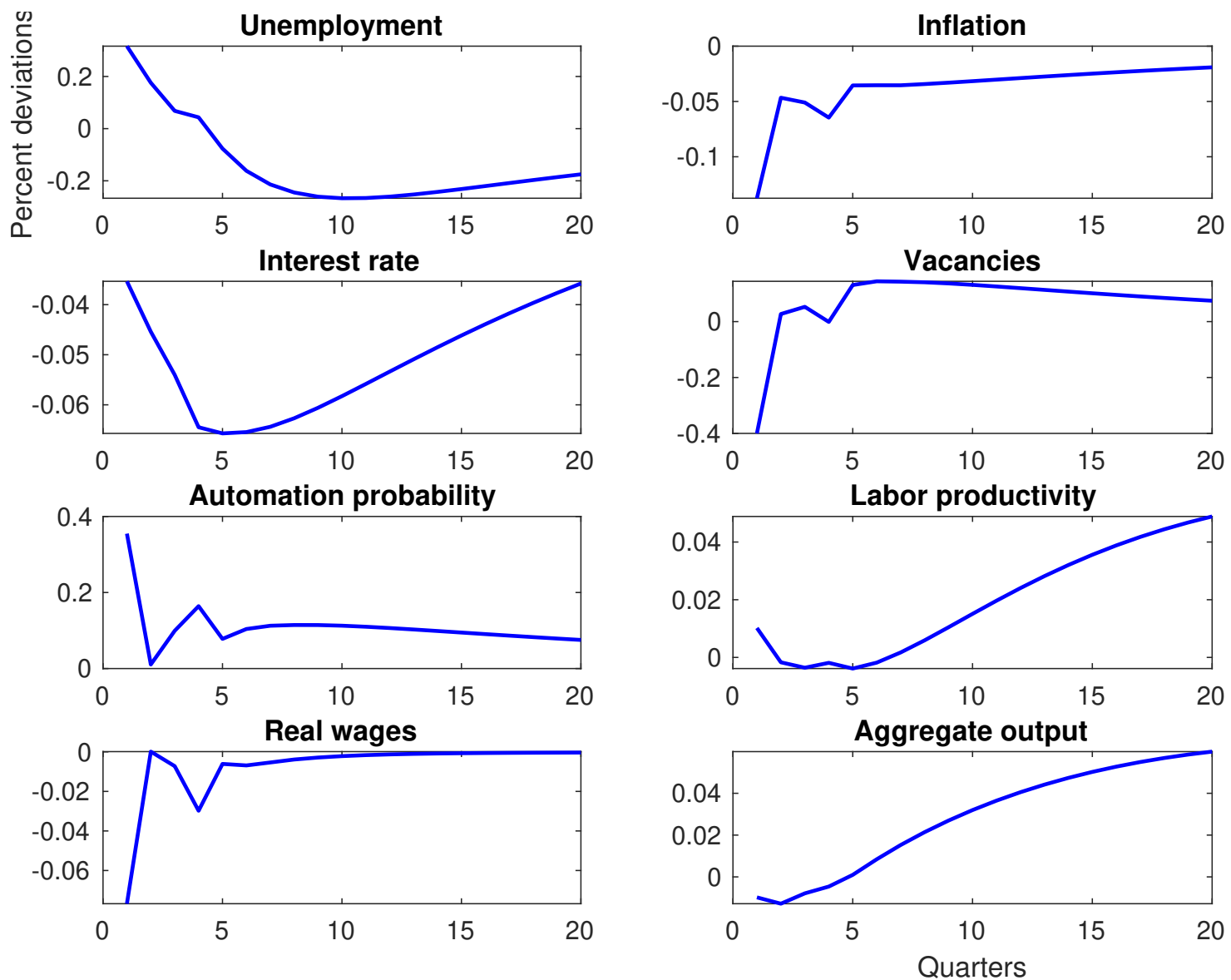

Figure A1. Impulse responses to a news shock to job uncertainty in the benchmark model. 

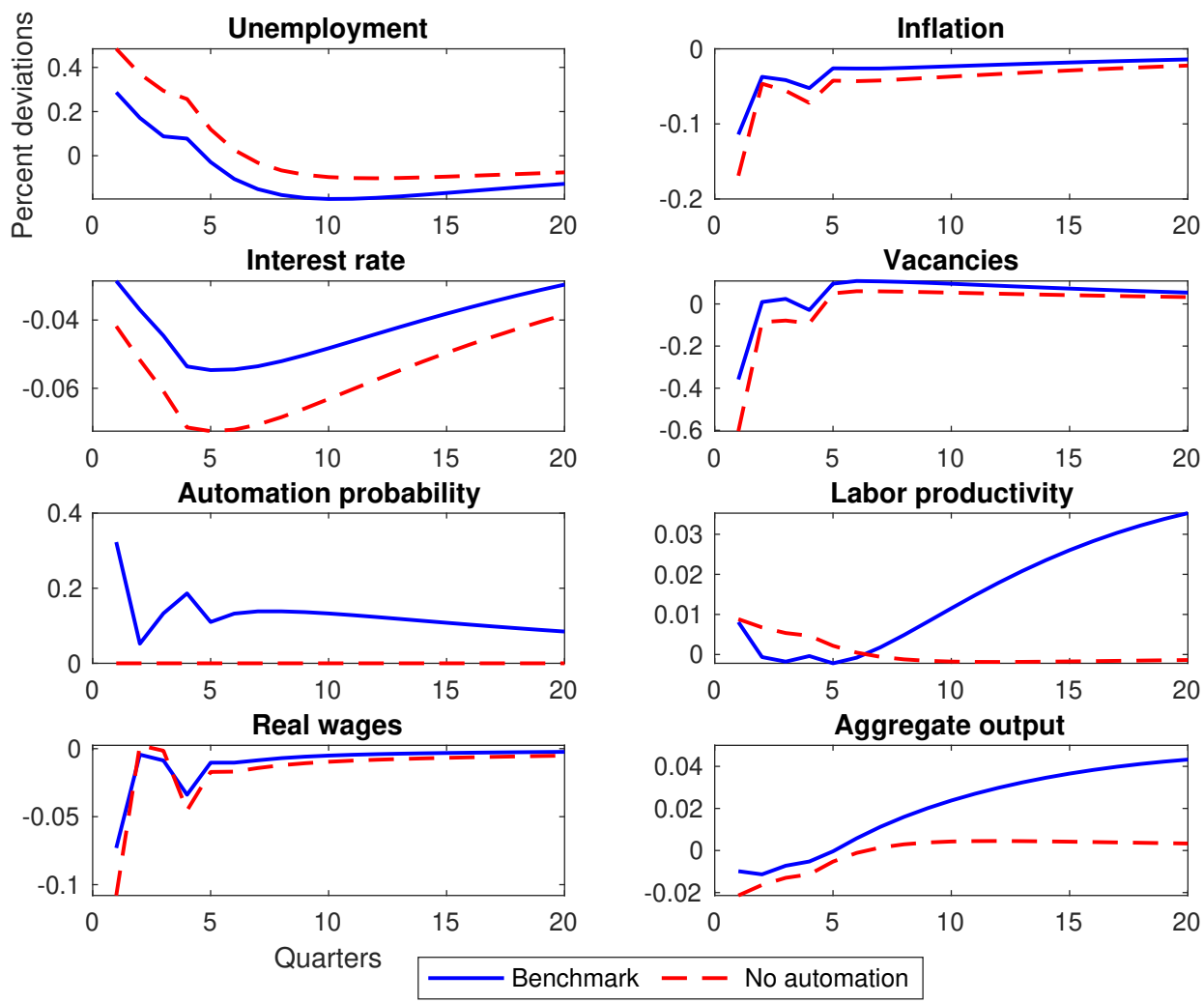

Figure A2. Impulse responses to a news shock to job uncertainty in the benchmark model (blue solid lines) and the counterfactual with no automation (red dashed lines). 

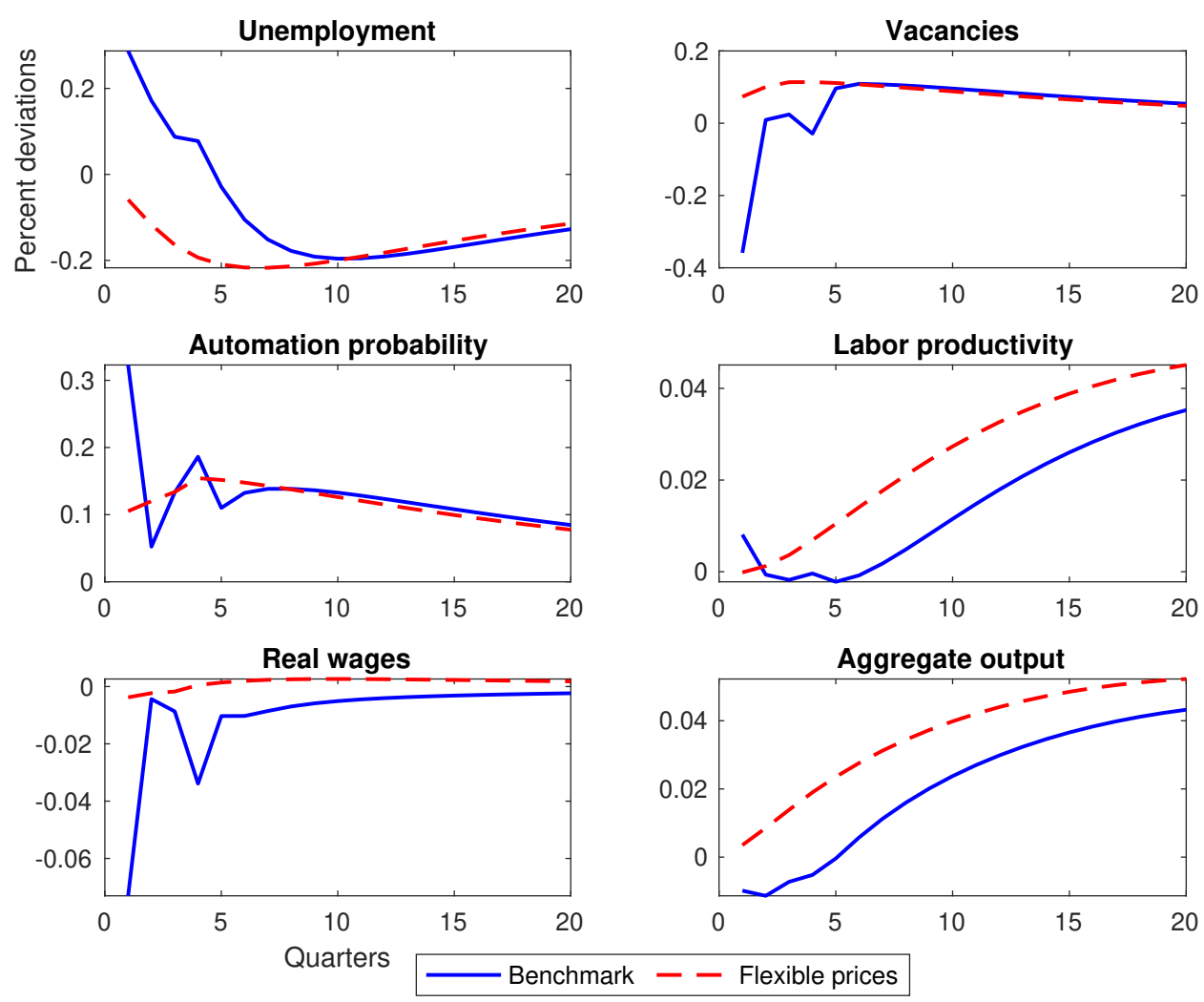

Figure A3. Impulse responses to a news shock to job uncertainty in the benchmark model (blue solid lines) and the flexible-price model (red dashed lines).

\section{Appendix E. Automating a Job instead of a Vacancy}

E.1. Summary of equilibrium conditions. A search equilibrium is a system of 21 equations for 21 variables summarized in the vector

$$
\left[C_{t}, R_{t}, \pi_{t}, p_{m t}, Y_{t}, m_{t}, u_{t}, v_{t}, q_{t}^{u}, q_{t}^{v}, q_{t}^{a}, N_{t}, U_{t}, \eta_{t}, J_{t}^{e}, J_{t}^{v}, J_{t}^{a}, w_{t}, A_{t}, x_{t}^{*}, \Lambda_{t}\right]
$$

We write the equations in the same order as in the dynare code.

(1) Household marginal utility of consumption:

$$
\Lambda_{t}=\frac{1}{C_{t}-\gamma_{c} C_{t-1}}-\mathbb{E}_{t} \frac{\beta \theta_{t+1} \gamma_{c}}{C_{t+1}-\gamma_{c} C_{t}}
$$

(2) Household's bond Euler equation:

$$
1=\mathrm{E}_{t} \beta \theta_{t+1} \frac{\Lambda_{t+1}}{\Lambda_{t}} \frac{R_{t}}{\pi_{t+1}}
$$

(3) Matching function

$$
m_{t}=\mu u_{t}^{\alpha} v_{t}^{1-\alpha}
$$


(4) Job finding rate

$$
q_{t}^{u}=\frac{m_{t}}{u_{t}}
$$

(5) Vacancy filling rate

$$
q_{t}^{v}=\frac{m_{t}}{v_{t}}
$$

(6) Employment dynamics

$$
N_{t}=\left(1-\delta_{t}\right)\left(1-q_{t}^{a}\right) N_{t-1}+m_{t},
$$

(7) Number of searching workers

$$
u_{t}=1-\left(1-\delta_{t}\right)\left(1-q_{t}^{a}\right) N_{t-1},
$$

(8) Unemployment

$$
U_{t}=1-N_{t},
$$

(9) Vacancy dynamics

$$
v_{t}=\left(1-q_{t-1}^{v}\right) v_{t-1}+\delta_{t} N_{t-1}+\eta_{t}
$$

(10) Automation dynamics

$$
A_{t}=\left(1-\rho^{o}\right) A_{t-1}+q_{t}^{a}\left(1-\delta_{t}\right) N_{t-1},
$$

(11) Automation value

$$
J_{t}^{a}=p_{m t} Z_{t} \zeta_{a t}\left(1-\kappa_{a}\right)+\left(1-\rho^{o}\right) \mathbb{E}_{t} \beta \theta_{t+1} \frac{\Lambda_{t+1}}{\Lambda_{t}} J_{t+1}^{a},
$$

(12) Vacancy value

$$
J_{t}^{v}=-\kappa+q_{t}^{v} J_{t}^{e}+\left(1-q_{t}^{v}\right) \mathbb{E}_{t} \beta \theta_{t+1} \frac{\Lambda_{t+1}}{\Lambda_{t}} J_{t+1}^{v} .
$$

(13) Employment value

$J_{t}^{e}=p_{m t} Z_{t} \zeta_{l t}-w_{t}+\mathbb{E}_{t} \beta \theta_{t+1} \frac{\Lambda_{t+1}}{\Lambda_{t}}\left\{\delta_{t+1} J_{t+1}^{v}+\left(1-\delta_{t+1}\right)\left[q_{t+1}^{a} J_{t+1}^{a}+\left(1-q_{t+1}^{a}\right) J_{t+1}^{e}\right]\right\}$,

(14) Automation threshold

$$
x_{t}^{*}=J_{t}^{a}-J_{t}^{e},
$$

(15) Robot adoption

$$
q_{t}^{a}=\left(\frac{x_{t}^{*}}{\bar{x}}\right)^{\eta_{a}}
$$

(16) Vacancy creation

$$
\eta_{t}=\left(\frac{J_{t}^{v}}{\bar{e}}\right)^{\eta_{e}}
$$

(17) Aggregate output

$$
Y_{t}=Z_{t} \zeta_{l t} N_{t}+Z_{t} \zeta_{a t} A_{t}
$$


(18) Resource constraint

$$
\begin{aligned}
Y_{t}= & C_{t}+G_{t}+\kappa v_{t}+\kappa_{a} Z_{t} \zeta_{a t} A_{t}+\frac{\eta_{a}}{1+\eta_{a}} q_{t}^{a} x_{t}^{*}\left(1-\delta_{t}\right) N_{t-1}+\frac{\eta_{e}}{1+\eta_{e}} \eta_{t} J_{t}^{v} \\
& +\frac{\Omega_{p}}{2}\left(\frac{\pi_{t}}{\pi_{t-1}^{\gamma_{p}} \pi^{1-\gamma_{p}}}-1\right)^{2} Y_{t},
\end{aligned}
$$

(19) Nash bargaining wage

$$
\frac{b}{1-b}\left(J_{t}^{e}-J_{t}^{v}\right)=w_{t}-\phi-\frac{\chi}{\Lambda_{t}}+\mathbb{E}_{t} \beta \theta_{t+1} \frac{\Lambda_{t+1}}{\Lambda_{t}}\left(1-q_{t+1}^{u}\right)\left(1-\delta_{t+1}\right) \frac{b}{1-b}\left(J_{t+1}^{e}-J_{t+1}^{v}\right),
$$

(20) With dynamic inflation indexation, the Phillips curve is given by

$$
p_{m t}=\frac{\epsilon-1}{\epsilon}+\frac{\Omega_{p}}{\epsilon}\left[\frac{\pi_{t}}{\pi_{t-1}^{\gamma_{p}} \pi^{1-\gamma_{p}}}\left(\frac{\pi_{t}}{\pi_{t-1}^{\gamma_{p}} \pi^{1-\gamma_{p}}}-1\right)-E_{t} \frac{\beta \theta_{t+1} \Lambda_{t+i}}{\Lambda_{t}} \frac{Y_{t+1}}{Y_{t}} \frac{\pi_{t+1}}{\pi_{t}^{\gamma_{p}} \pi^{1-\gamma_{p}}}\left(\frac{\pi_{t+1}}{\pi_{t}^{\gamma_{p}} \pi^{1-\gamma_{p}}}-1\right)(\mathrm{A}\right.
$$

where $\gamma_{p}$ measures the importance of dynamic indexation.

(21) Taylor rule

$$
\frac{R_{t}}{R}=\left(\frac{R_{t-1}}{R}\right)^{\rho_{r}}\left[\left(\frac{\pi_{t}}{\pi}\right)^{\phi_{\pi}}\left(\frac{U_{t}}{U_{t}^{*}}\right)^{-\frac{\phi_{u}}{4}}\right]^{1-\rho_{r}} \exp \left(\varepsilon_{r t}\right)
$$

E.2. Parameter estimation. The calibrated parameters are the same as in the baseline model (see Table 1). We estimate the model in which firms can automate an existing job instead of a vacancy, using the same six time series described in main text. Table A2 shows the estimation results. 
TABLE A2. Estimated parameters in the model in which jobs can be automated

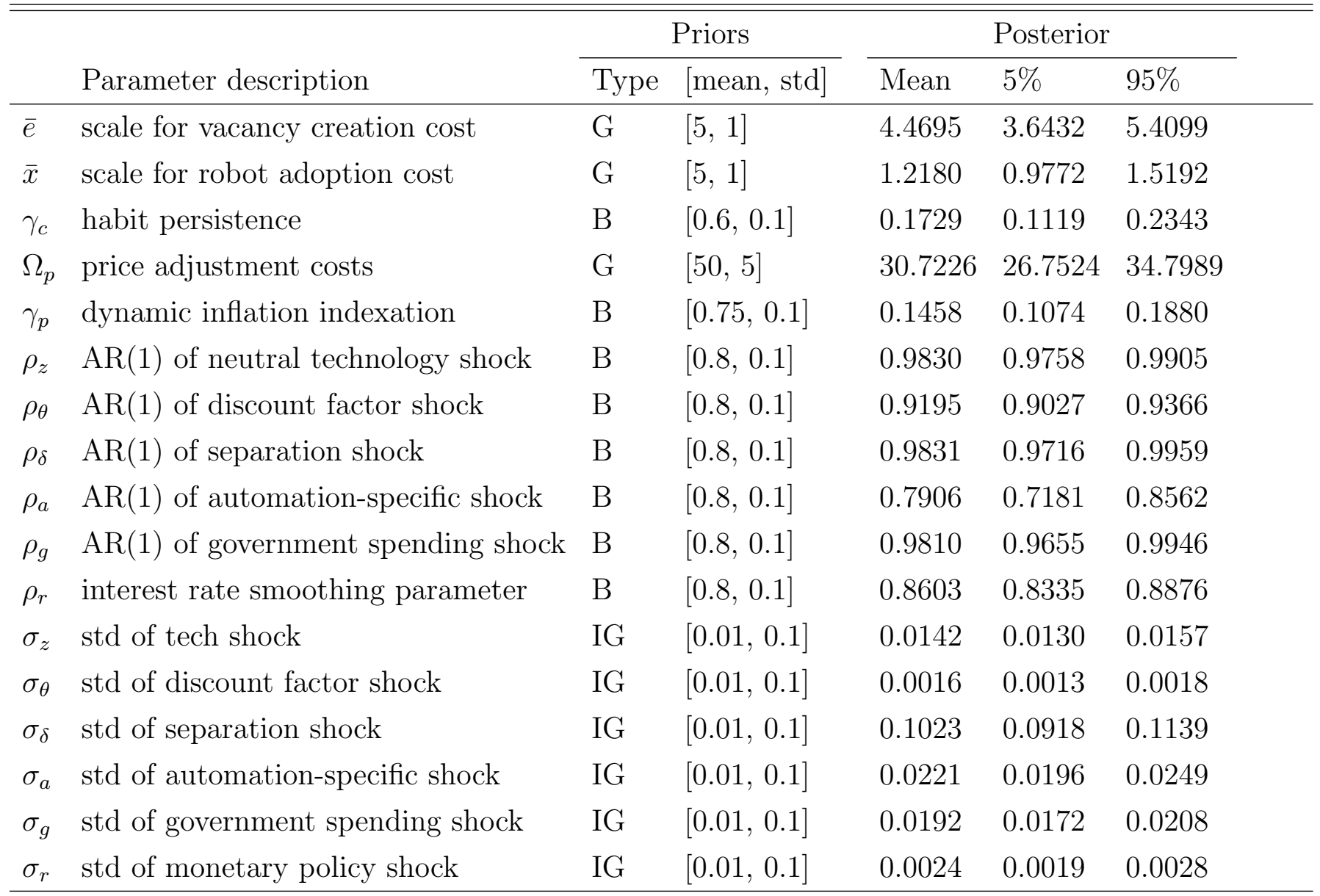

Note: This table shows our estimation results in the alternative setup where firms can automate an existing job instead of an unfilled vacancy. For the prior distribution types, we use G to denote the gamma distribution, B the beta distribution, and IG the inverse gamma distribution. 